\title{
Polymeric Nanoparticles Integrated from Discrete Organoplatinum(II) Metallacycle by Stepwise Post-Assembly Polymerization for Synergistic Cancer Therapy
}

Jiong Zhou, ${ }^{\dagger}$ Guocan Yu, ${ }^{*}, \star$ Jie Yang,${ }^{\dagger}$ Bingbing Shi,${ }^{\S}$ Boyong Ye,${ }^{\dagger}$ Mengbin Wang,${ }^{\dagger}$ Feihe Huang $, *, \dagger, \#$ and Peter J. Stang*,§

${ }^{\dagger}$ State Key Laboratory of Chemical Engineering, Center for Chemistry of High-Performance and Novel Materials, Department of Chemistry, Zhejiang University, Hangzhou 310027, P. R. China

Laboratory of Molecular Imaging and Nanomedicine, National Institute of Biomedical Imaging and Bioengineering, National Institutes of Health, Bethesda, Maryland 20892, United States

${ }^{\S}$ Department of Chemistry, University of Utah, 315 South 1400 East, Room 2020, Salt Lake City, Utah 84112, United States

${ }^{\#}$ Green Catalysis Center and College of Chemistry, Zhengzhou University, Zhengzhou 450001, P. R. China

Email addresses: guocan.yu@nih.gov; fhuang@zju.edu.cn; stang@chem.utah.edu

\section{Supporting Information (31 pages)}

1. Materials and methods

2. Synthesis and self-assembly of supramolecular block copolymers

3. In vitro and in vivo anticancer studies 


\section{Materials and methods}

Poly(ethylene glycol) methacrylate (OEGMA, $\left.M_{\mathrm{n}}=500\right)$ and other reagents were purchased from Sigma-Aldrich and used as received. Solvents were either employed as purchased or dried according to procedures described in the literature. NMR spectra were recorded on a Bruker Avance III-400 spectrometry with internal standard TMS. ${ }^{31} \mathrm{P}\left\{{ }^{1} \mathrm{H}\right\}$ NMR chemical shifts are referenced to an external unlocked sample of $85 \% \mathrm{H}_{3} \mathrm{PO}_{4}(\delta=0.0)$. High-resolution mass spectrometry experiments were performed with a Bruker 7-Tesla FT-ICR mass spectrometer equipped with an electrospray source (Billerica, MA, USA). The fluorescence experiments were conducted on a Horiba Fluoromax-4 spectrometer. Transmission electron microscopy (TEM) investigations were carried out on a Jeol JEM 2010 instrument. The fluorescence experiments were conducted on a RF-5301 spectrofluorophotometer (Shimadzu Corporation, Japan). Dynamic light scattering (DLS) measurements were carried out using a $200 \mathrm{~mW}$ polarized laser source Nd:YAG $(\lambda=532 \mathrm{~nm})$. The polarized scattered light was collected at $90^{\circ}$ in a self-beating mode with a Hamamatsu R942/02 photomultiplier. The signals were sent to a Malvern 4700 submicrometer particle analyzer system.

Preparation of PA-loaded Pt NPs (Pt NPs@PA) and DOX-loaded Pt NPs (Pt NPs@DOX). For drug loading, neutral DOX was used by deprotonating the cationic drug. Briefly, cationic DOX (20.0 mg) was solublized in the mixture of distilled water $(5 \mathrm{~mL})$ and THF $(5 \mathrm{~mL})$, one drop of triethylamine was added and the solution was stirred for $15 \mathrm{~min}$. Then the organic solvent was removed by vacuum rotary. The formed precipitation was collected by centrifugation and dried under vacuum for further use. Pt NPs@PA (or Pt NPs@DOX) were obtained through a re-precipitation method. Briefly, Pt-PBEMA-b-POEGMA or Pt-PBrEMA-b-POEGMA (100 mg) and PA (or DOX, $40.0 \mathrm{mg}$ ) were dissolved in $30 \mathrm{~mL}$ of THF, and the solution was gradually injected into $250 \mathrm{~mL}$ of MilliQ water under sonication. The mixture was then stirred at $600 \mathrm{rpm}$ at room temperature in dark overnight for the evaporation of THF. The resulting mixture was sealed in dialysis bags with a molecular weight cut-off of $3 \mathrm{kDa}$ and dialyzed against DI water for $2 \mathrm{~h}$ to remove unloaded drugs. The same method was utilized for the preparation of $\mathbf{P t}$ NPs@PA/DOX ( $n$ Pt NPs@PA/DOX). The mass of Pt-PBEMA- $b$-POEGMA (or Pt-PBrEMA- $\boldsymbol{b}$-POEGMA) was $100 \mathrm{mg}$ and the mass of PA/DOX mixture with different ratios was 40.0 mg. The drug encapsulation was calculated by using the following equation:

Drug loading content $(\%)=\left[m_{\text {drug-loaded }} /\left(m_{\text {polymer }}+m_{\text {drug-loaded }}\right)\right]^{* 100}$

where the $m_{\text {drug-loaded }}$ and $m_{\text {polymer }}$ are the masses of the encapsulated drug in the nanostructures and the polymer, respectively.

Transmission Electron Microscopy (TEM) and Dynamic Light Scattering (DLS) Studies. The morphology of nanoformulations was revealed using TEM. TEM samples were prepared by drop-coating 
the corresponding solution onto a carbon-coated copper grid. The size and stability of Pt NPs@PA/DOX was confirmed by measuring their mean diameters after different periods of incubation by DLS tests.

Cell Culture. HeLa cells were purchased from the American Type Culture Collection (ATCC, Rockville MD) and cultured in Dulbecco's modified Eagle's medium (DMEM) containing 10\% fetal bovine serum (FBS) and 1\% penicillin/streptomycin. Cells grew as a monolayer and were detached upon confluence using trypsin $(0.5 \% \mathrm{w} / v$ in PBS). The cells were harvested from cell culture medium by incubating in trypsin solution for $5 \mathrm{~min}$. The cells were centrifuged, and the supernatant was discarded. A $3.00 \mathrm{~mL}$ portion of serum-supplemented DMEM was added to neutralize any residual trypsin. The cells were resuspended in serum-supplemented DMEM at a concentration of $1.00 \times 10^{4}$ cells $/ \mathrm{mL}$. Cells were cultured at $37{ }^{\circ} \mathrm{C}$ and $5 \% \mathrm{CO}_{2}$.

Evaluation of Cytotoxicity. The cytotoxicity against $\mathrm{HeLa}$ cells were determined by 3-(4,5-dimethylthiazol-2-yl)-2,5-diphenyl tetrazolium bromide (MTT) assay in a 96-well cell culture plate. All solutions were sterilized by filtration with a $0.22 \mu \mathrm{m}$ filter before tests. HeLa cells were seeded at a density of $1.00 \times 10^{4}$ cells/well in a 96-well plate, and incubated for $24 \mathrm{~h}$ for attachment. Cells were then incubated with PA, DOX, Pt NPs@PA, Pt NPs@DOX, Pt NPs@PA/DOX, and $n$ Pt NPs@PA/DOX at various concentrations for $48 \mathrm{~h}$. After washing the cells with PBS buffer, $20 \mu \mathrm{L}$ of a MTT solution (5.00 $\mathrm{mg} / \mathrm{mL}$ ) was added to each well. After $4 \mathrm{~h}$ of incubation at $37{ }^{\circ} \mathrm{C}$, the MTT solution was removed, and the insoluble formazan crystals that formed were dissolved in $100 \mu \mathrm{L}$ of dimethylsulfoxide (DMSO). The absorbance of the formazan product was measured at $570 \mathrm{~nm}$ using a spectrophotometer (Bio-Rad Model 680). Untreated cells in media were used as a control. All experiments were carried out with five replicates.

\section{In Vitro Cell Accumulation of the Determined by Confocal Laser Scanning Microscopy (CLSM).} HeLa cells were treated with the Pt NPs@PA/DOX or $n$ Pt NPs@PA/DOX (the concentration of DOX was kept at $1.00 \mu \mathrm{M}$ ) in the culture medium at $37{ }^{\circ} \mathrm{C}$ for $4 \mathrm{~h}$ and $8 \mathrm{~h}$. The cells were washed three times with PBS and fixed with fresh $4.0 \%$ formaldehyde at room temperature for 15 min. After washing with PBS, the cells were stained with lysotracker green $(200 \mathrm{nM})$ and 4',6-diamidino-2-phenylindole (DAPI). The images were taken using a LSM-510 confocal laser scanning microscope (CLSM, ZEISS LSM780).

Tumor Model. Nude mice (4 weeks old, 20 g body weight) were purchased from Zhejiang Academy of Medical Sciences and maintained in a pathogen-free environment under controlled temperature $\left(24{ }^{\circ} \mathrm{C}\right)$. Study protocols involving animals were approved by the Zhejiang University Animal Care and Use Committee. The nude mice were injected subcutaneously in the right flank region with $200 \mu \mathrm{L}$ of cell 
suspension containing $5 \times 10^{6} \mathrm{HeLa}$ cells. The tumors were allowed to grow to $\sim 100 \mathrm{~mm}^{3}$ before experimentation. The tumor volume was calculated as (tumor length) $\times(\text { tumor width })^{2} / 2$. Relative tumor volumes were calculated as $V / V_{0}\left(V_{0}\right.$ was the tumor volume when the treatment was initiated).

Pharmacokinetics and Tissue Distributions. Mice received DOX (5.00 mg/kg) or Pt NPs@PA/DOX $(5.00 \mathrm{mg} \mathrm{DOX} / \mathrm{kg})$ by tail vein injection. Blood was collected by cardiac puncture and kept in heparinized tubes. The liver, lung, spleen, kidney and tumor were excised after i.v. injection for $24 \mathrm{~h}$ and kept in dry ice before analysis. Organs were digested and the amount of DOX was analyzed by HPLC.

In Vivo Antitumor Activity. Tumor volume and body weights were measured for individual animals in all experiments. The mice were divided into five treatment groups randomly $(n=5)$, when the mean tumor volume reached about $100 \mathrm{~mm}^{3}$ and this day was set as day 0. Mice were administered intravenously with PBS, DOX (5.00 mg/kg), Pt NPs@PA, Pt NPs@DOX (5.00 mg DOX/kg), nPt NPs@PA/DOX (5.00 mg DOX/kg), or Pt NPs@PA/DOX (5.00 mg DOX/kg) every 3 days for three times. Tumor volume and body weight were measured every 3 days.

Tissue Histopathology Evaluation. In the histological assay, the heart, liver, spleen, lung, kidney and tumor tissues were fixed in $4 \%$ paraformaldehyde for $24 \mathrm{~h}$. The specimens were dehydrated in graded ethanol, embedded in paraffin, and cut into $5 \mathrm{~mm}$ thick sections. The fixed sections were deparaffinized and hydrated according to a standard protocol and stained with hematoxylin and eosin (H\&E) for microscopic observation.

Statistical Analysis. Data are expressed as mean standard deviation (SD). Analysis of variance (ANOVA), followed by Student's $t$-test, was used to determine the significant differences among the groups $(* * P<0.01$, and $* * * P<0.001)$. 
2. Synthesis and self-assembly of supramolecular block copolymers

\subsection{Synthesis of BEMA}

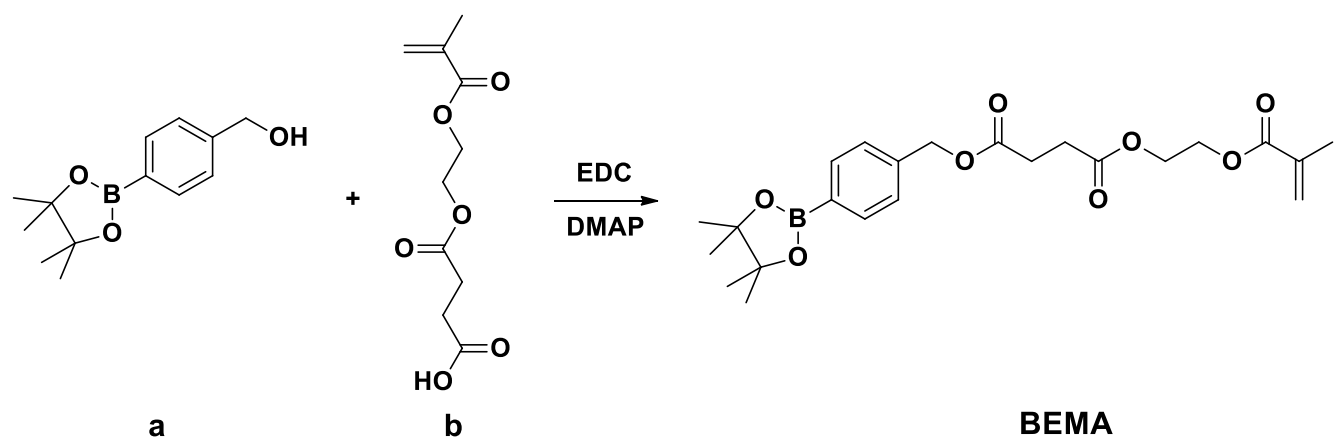

Scheme S1. Synthetic route to BEMA.

To a solution of a $(1.64 \mathrm{~g}, 5.00 \mathrm{mmol})$ and $\mathbf{b}(0.570 \mathrm{~g}, 2.50 \mathrm{mmol})$ in dry $\mathrm{CH}_{2} \mathrm{Cl}_{2}(100 \mathrm{~mL})$,

4-dimethylaminopyridine

(DMAP,

catalytic

amount)

and

1-(3'-dimethylaminopropyl)-3-ethylcarbodiimide hydrochloride (EDC, 1.79 g, $10.0 \mathrm{mmol}$ ) were added under nitrogen atmosphere. The mixture was stirred overnight at room temperature. The solution was evaporated under vacuo and the residue was purified by flash column chromatography on silica gel (dichloromethane/petroleum ether $=1: 2, v / v$ ) to afford BEMA as an oil with a yield of $64 \%$. The ${ }^{1} \mathrm{H}$ NMR spectrum of BEMA is shown in Figure S1. ${ }^{1} \mathrm{H}$ NMR (400 MHz, DMSO- $\left.d_{6}, 293 \mathrm{~K}\right) \delta$ (ppm): 7.67 $(\mathrm{d}, J=8 \mathrm{~Hz}, 2 \mathrm{H}), 7.35(\mathrm{~d}, J=8 \mathrm{~Hz}, 2 \mathrm{H}), 6.02(\mathrm{~s}, 1 \mathrm{H}), 5.66(\mathrm{~s}, 1 \mathrm{H}), 5.11(\mathrm{~s}, 2 \mathrm{H}), 4.27(\mathrm{~s}, 4 \mathrm{H}), 2.61(\mathrm{~s}, 4 \mathrm{H})$, $1.86(\mathrm{~s}, 3 \mathrm{H}), 1.29$ (s, 12H). The ${ }^{13} \mathrm{C}$ NMR spectrum of BEMA is shown in Figure S2. ${ }^{13} \mathrm{C}$ NMR (100 MHz, DMSO- $d_{6}, 293$ K) $\delta(\mathrm{ppm}): 171.79,171.67,166.37,139.38,135.57,134.51,126.99,126.08,83.67$, 65.36, 62.37, 62.00, 28.52, 24.64, 17.90. HRESI-MS is shown in Figure S3: $m / z$ 447.1542 [M + H] $]^{+}$ 


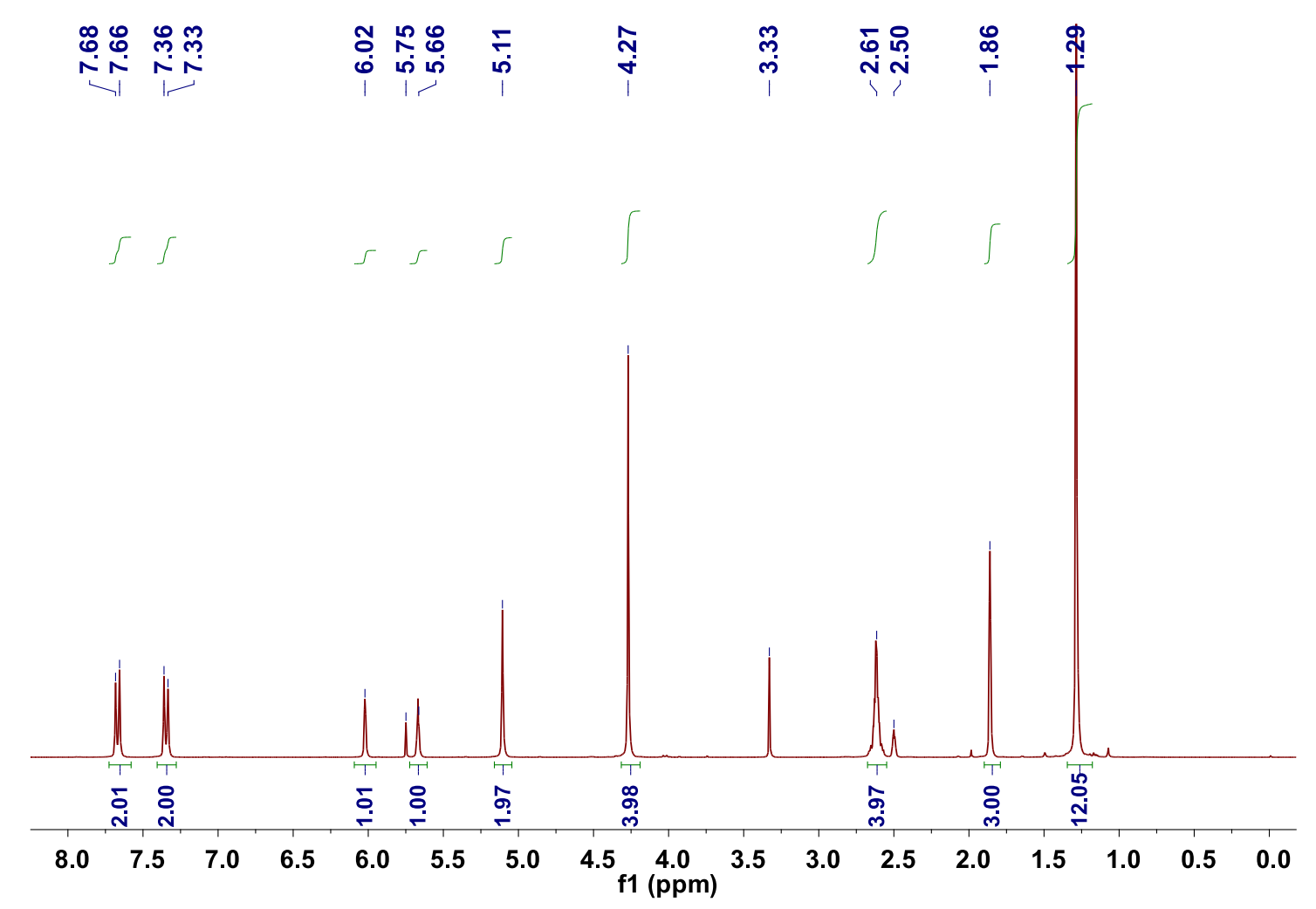

Figure S1. ${ }^{1} \mathrm{H}$ NMR spectrum (400 MHz, DMSO- $d_{6}$, $\left.293 \mathrm{~K}\right)$ of BEMA.

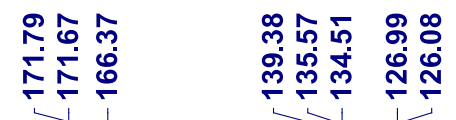
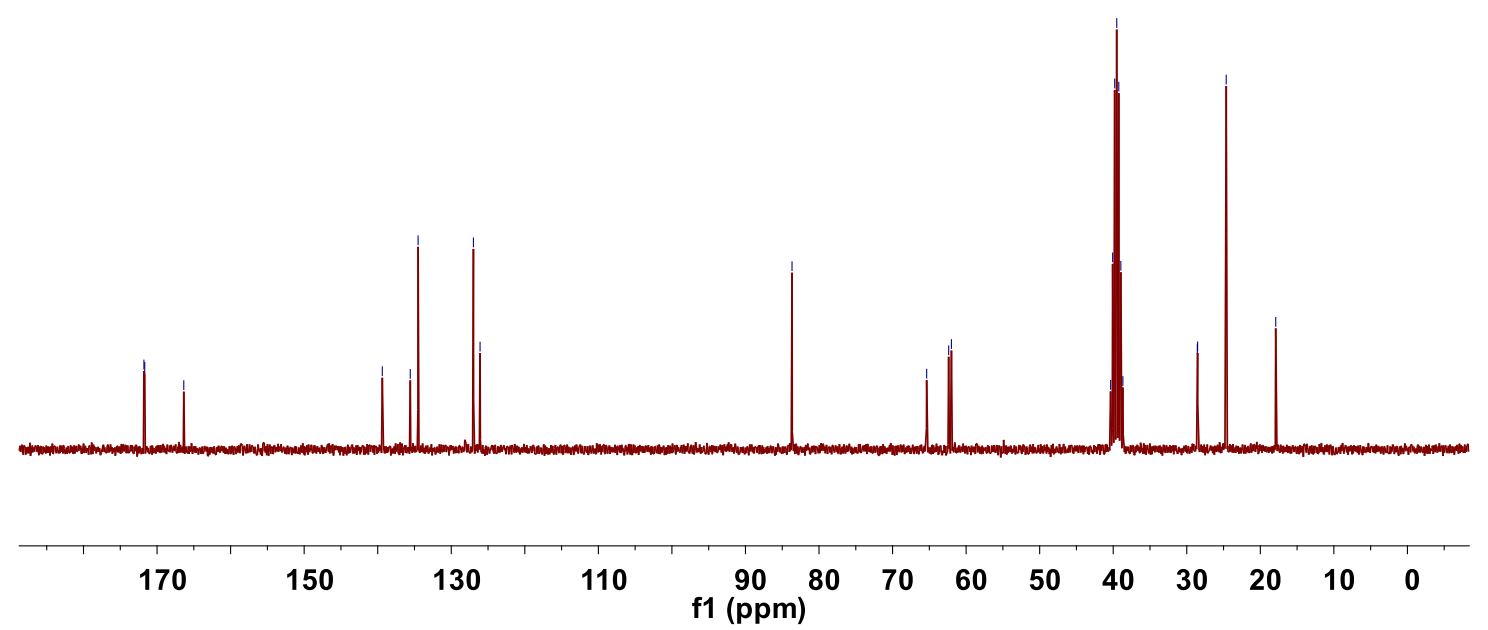

Figure S2. ${ }^{13} \mathrm{C}$ NMR spectrum $\left(100 \mathrm{MHz}\right.$, DMSO- $\left.d_{6}, 293 \mathrm{~K}\right)$ of BEMA. 


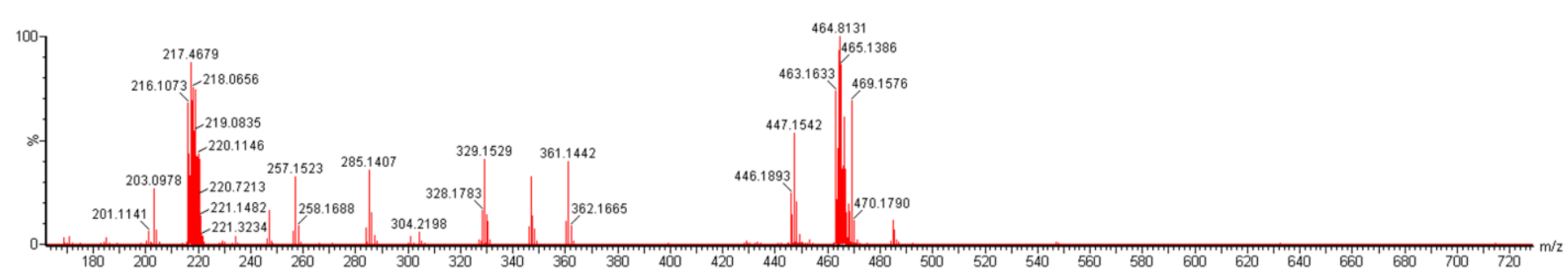

Figure S3. High-resolution electrospray ionization mass spectrum (HRESI-MS) of BEMA. Assignment of the main peak: $m / z 447.1542[\mathrm{M}+\mathrm{H}]^{+}$.

\subsection{Synthesis of BrEMA}

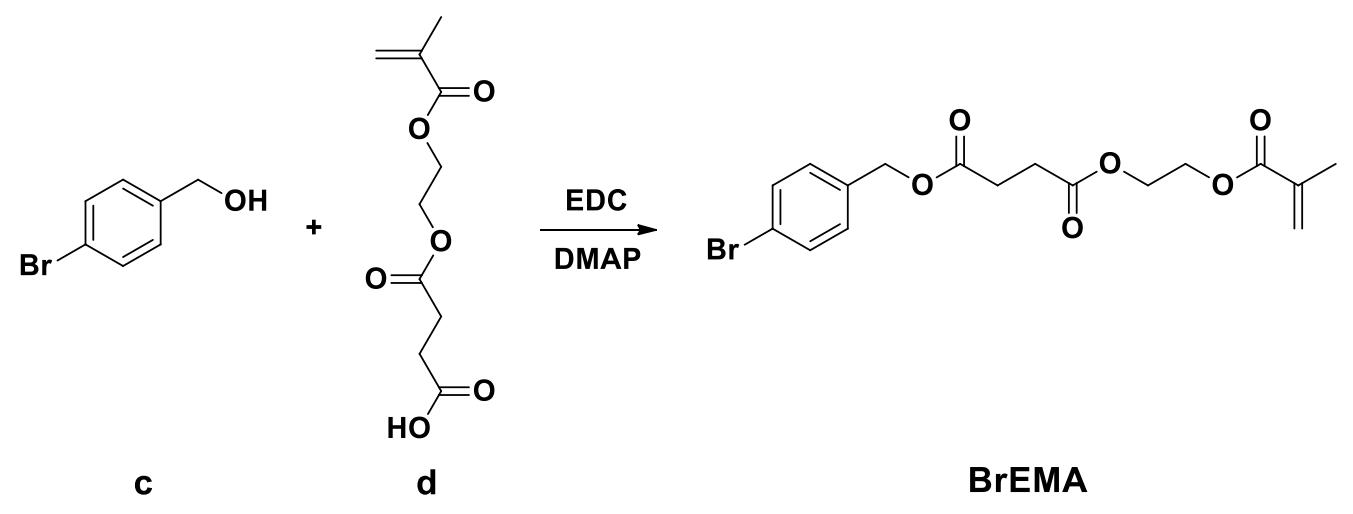

Scheme S2. Synthetic route to BrEMA.

To a solution of $\mathbf{c}(0.930 \mathrm{~g}, 5.00 \mathrm{mmol})$ and $\mathbf{d}(0.570 \mathrm{~g}, 2.50 \mathrm{mmol})$ in dry $\mathrm{CH}_{2} \mathrm{Cl}_{2}(100 \mathrm{~mL})$,

4-dimethylaminopyridine (DMAP, catalytic amount) and 1-(3'-dimethylaminopropyl)-3-ethylcarbodiimide hydrochloride (EDC, $1.79 \mathrm{~g}, 10.0 \mathrm{mmol}$ ) were added under nitrogen atmosphere. The mixture was stirred overnight at room temperature. The solution was evaporated under vacuo and the residue was purified by flash column chromatography on silica gel (dichloromethane/petroleum ether $=1: 2, v / v)$ to afford BrEMA as a white solid with a yield of 52\%. The ${ }^{1} \mathrm{H}$ NMR spectrum of BrEMA is shown in Figure S4. ${ }^{1} \mathrm{H}$ NMR (400 MHz, $\left.\mathrm{CDCl}_{3}, 293 \mathrm{~K}\right) \delta(\mathrm{ppm}): 7.49$ (d, $J=8 \mathrm{~Hz}, 2 \mathrm{H}), 7.22(\mathrm{~d}, J=8 \mathrm{~Hz}, 2 \mathrm{H}), 6.12(\mathrm{~s}, 1 \mathrm{H}), 5.59$ (s, 1H), 5.07 (s, 2H), 4.33 (s, 4H), 2.67 (s, 3H), $1.94(\mathrm{~s}, 3 \mathrm{H})$. The ${ }^{13} \mathrm{C}$ NMR spectrum of BrEMA is shown in Figure S5. ${ }^{13} \mathrm{C} \mathrm{NMR}\left(100 \mathrm{MHz}, \mathrm{CDCl}_{3}\right.$, $293 \mathrm{~K}) \delta$ (ppm): 171.86, 171.80, 166.95, 135.84, 134.79, 131.62, 129.80, 126.01, 122.19, 65.61, 62.36, 62.25, 28.93, 28.84, 18.19. HRESI-MS is shown in Figure S6: $m / z$ 399.0274 $[\mathrm{M}+\mathrm{H}]^{+}$. 


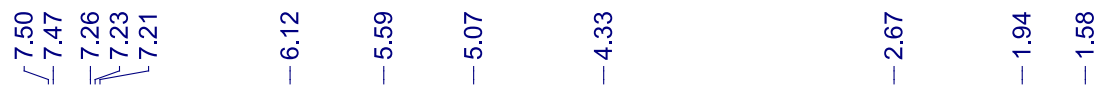

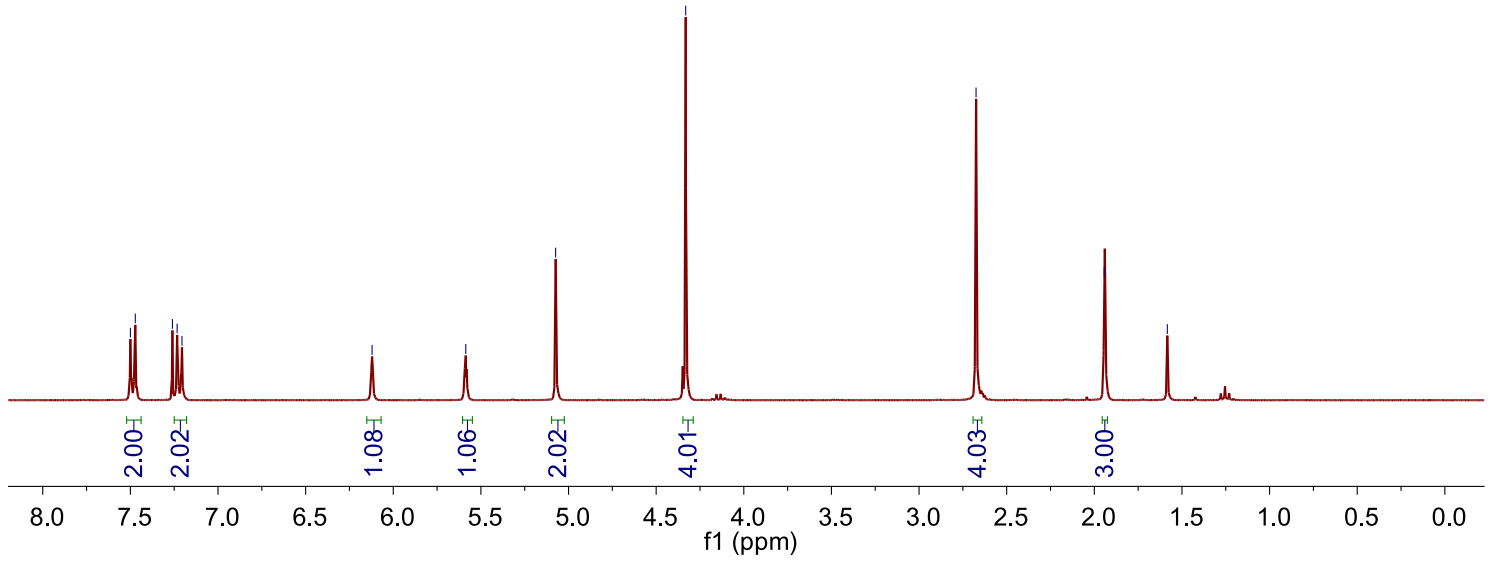

Figure S4. ${ }^{1} \mathrm{H}$ NMR spectrum (400 MHz, $\mathrm{CDCl}_{3}, 293 \mathrm{~K}$ ) of BrEMA.

\section{용}

돈휴융

๘๐

மึ่

유눈

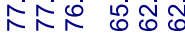

$\begin{array}{ll}m \\ \substack{\infty \\ \infty} & 0 \\ \infty & \infty \\ \infty & \infty\end{array}$

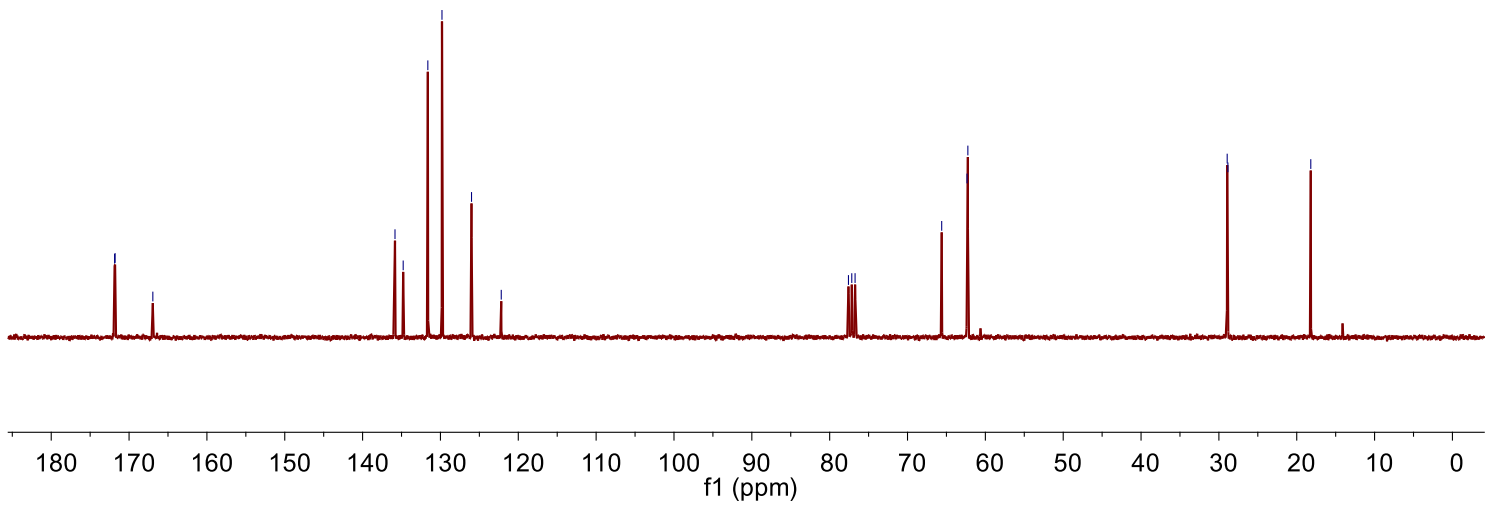

Figure S5. ${ }^{13} \mathrm{C}$ NMR spectrum $\left(100 \mathrm{MHz}, \mathrm{CDCl}_{3}, 293 \mathrm{~K}\right)$ of BrEMA. 


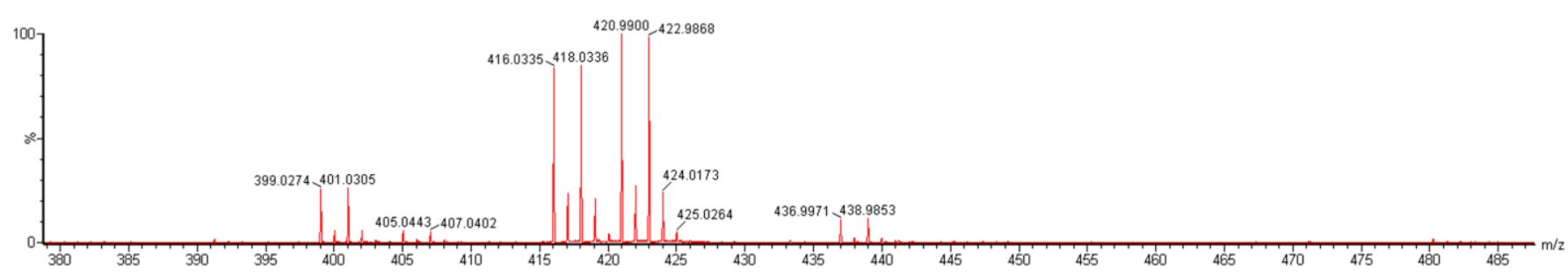

Figure S6. High-resolution electrospray ionization mass spectrum (HRESI-MS) of BrEMA. Assignment of the main peak: $m / z 399.0274[\mathrm{M}+\mathrm{H}]^{+}$.

\subsection{Synthesis of $120^{\circ}$ dipyridyl functionalized chain transfer agent 1}

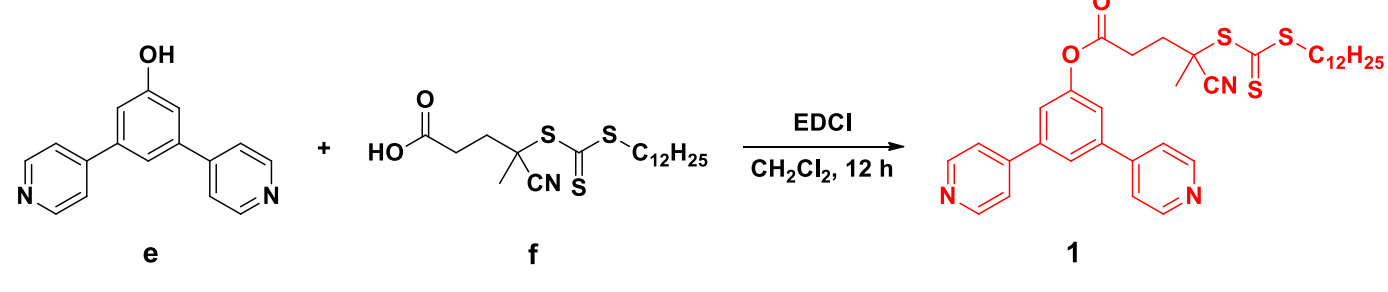

Scheme S3. Synthetic route to 1.

A $200 \mathrm{~mL}$ Schlenk flask was charged with e $(124 \mathrm{mg}, 0.500 \mathrm{mmol})$, f $(202 \mathrm{mg}, 0.500 \mathrm{mmol})$, and 1-(3-dimethylaminopropyl)-3-ethylcarbodiimide hydrochloride (EDCI) (384 mg, $2.00 \mathrm{mmol}$ ), degassed, and back filled three times with $\mathrm{N}_{2}$. Anhydrous dichloromethane $(20.0 \mathrm{~mL})$ were introduced into the reaction flask by syringe. The reaction mixture was stirred under an inert atmosphere at $0{ }^{\circ} \mathrm{C}$ for $2 \mathrm{~min}$ and $12 \mathrm{~h}$ at room temperature. The solvent was then removed under reduced pressure. The residue was purified by column chromatography on silica gel (dichloromethane/petroleum ether =1/1) to afford 1 as a light yellow solid with a yield of $46 \%$. The ${ }^{1} \mathrm{H}$ NMR spectrum of $\mathbf{1}$ is shown in Figure S7. ${ }^{1} \mathrm{H}$ NMR (400 $\left.\mathrm{MHz}, \mathrm{CDCl}_{3}, 293 \mathrm{~K}\right) \delta(\mathrm{ppm}): 8.72(\mathrm{~d}, J=8 \mathrm{~Hz}, 4 \mathrm{H}), 7.72(\mathrm{t}, J=4 \mathrm{~Hz}, 1 \mathrm{H}), 7.54(\mathrm{~d}, J=4 \mathrm{~Hz}, 4 \mathrm{H}), 7.43$ (d, $J=4 \mathrm{~Hz}, 2 \mathrm{H}), 3.33$ (t, $J=8 \mathrm{~Hz}, 2 \mathrm{H}), 1.88(\mathrm{~s}, 5 \mathrm{H}), 1.64-1.72(\mathrm{~m}, 4 \mathrm{H}), 1.37-1.42$ (m, 2H), 1.24 (s, $16 \mathrm{H}), 0.87$ (t, $J=8 \mathrm{~Hz}, 3 \mathrm{H})$. The ${ }^{13} \mathrm{C}$ NMR spectrum of 1 is shown in Figure S8. ${ }^{13} \mathrm{C}$ NMR $(100 \mathrm{MHz}$, $\left.\mathrm{CDCl}_{3}, 293 \mathrm{~K}\right) \delta(\mathrm{ppm}): 171.84,152.38,150.49,147.14,140.69,123.34,121.87,120.93,55.89,37.39$, $32.02,29.72,29.64,29.54,29.45,29.22,29.05,27.98,25.45,22.80,14.24$. 


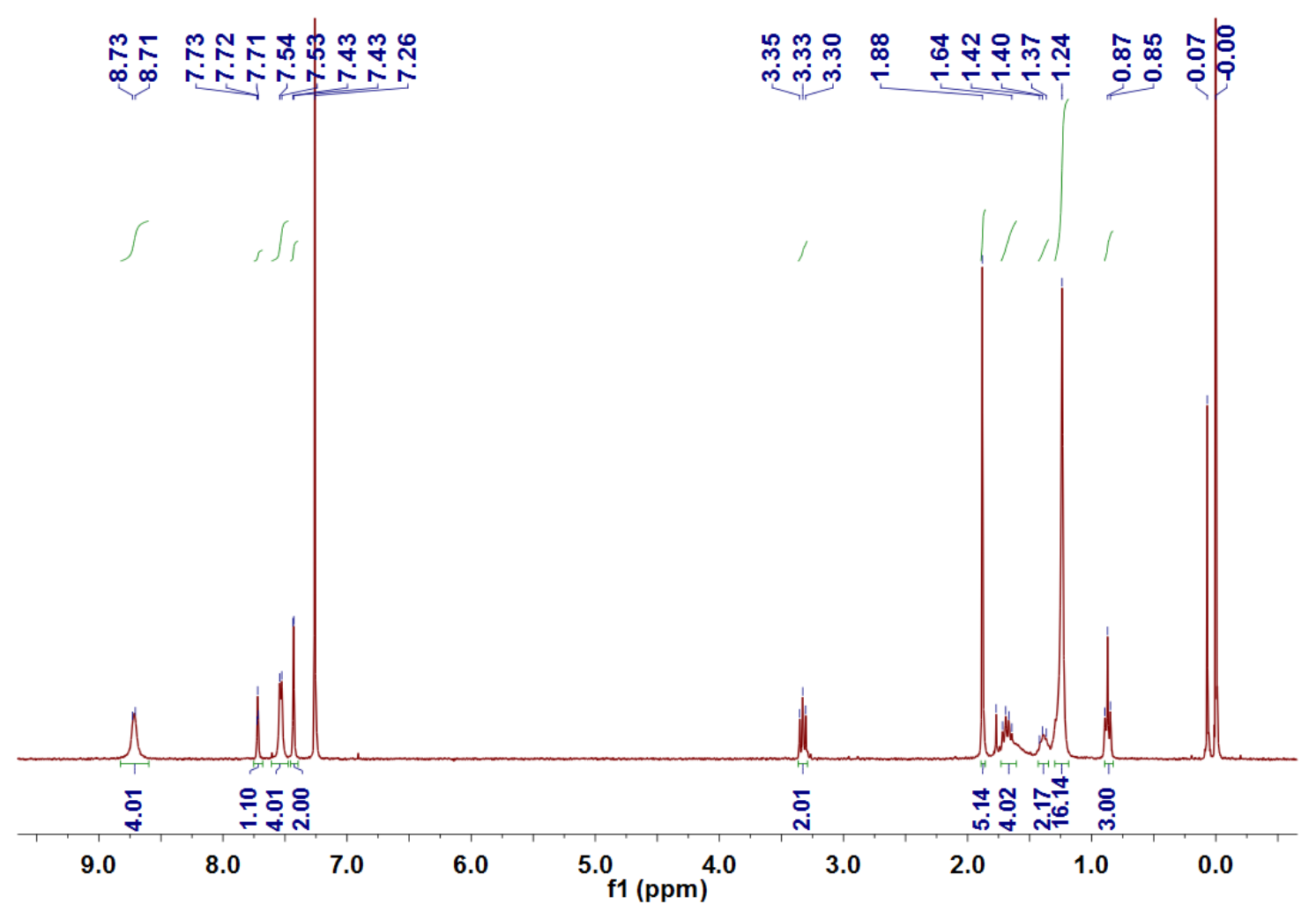

Figure S7. ${ }^{1} \mathrm{H}$ NMR spectrum $\left(400 \mathrm{MHz}, \mathrm{CDCl}_{3}, 293 \mathrm{~K}\right)$ of $\mathbf{1}$.

\begin{tabular}{|c|c|c|c|c|}
\hline 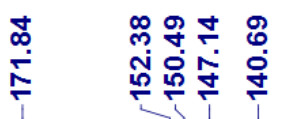 & 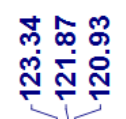 & 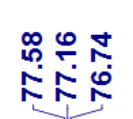 & 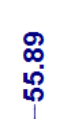 & 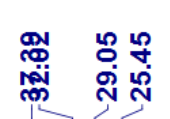 \\
\hline
\end{tabular}

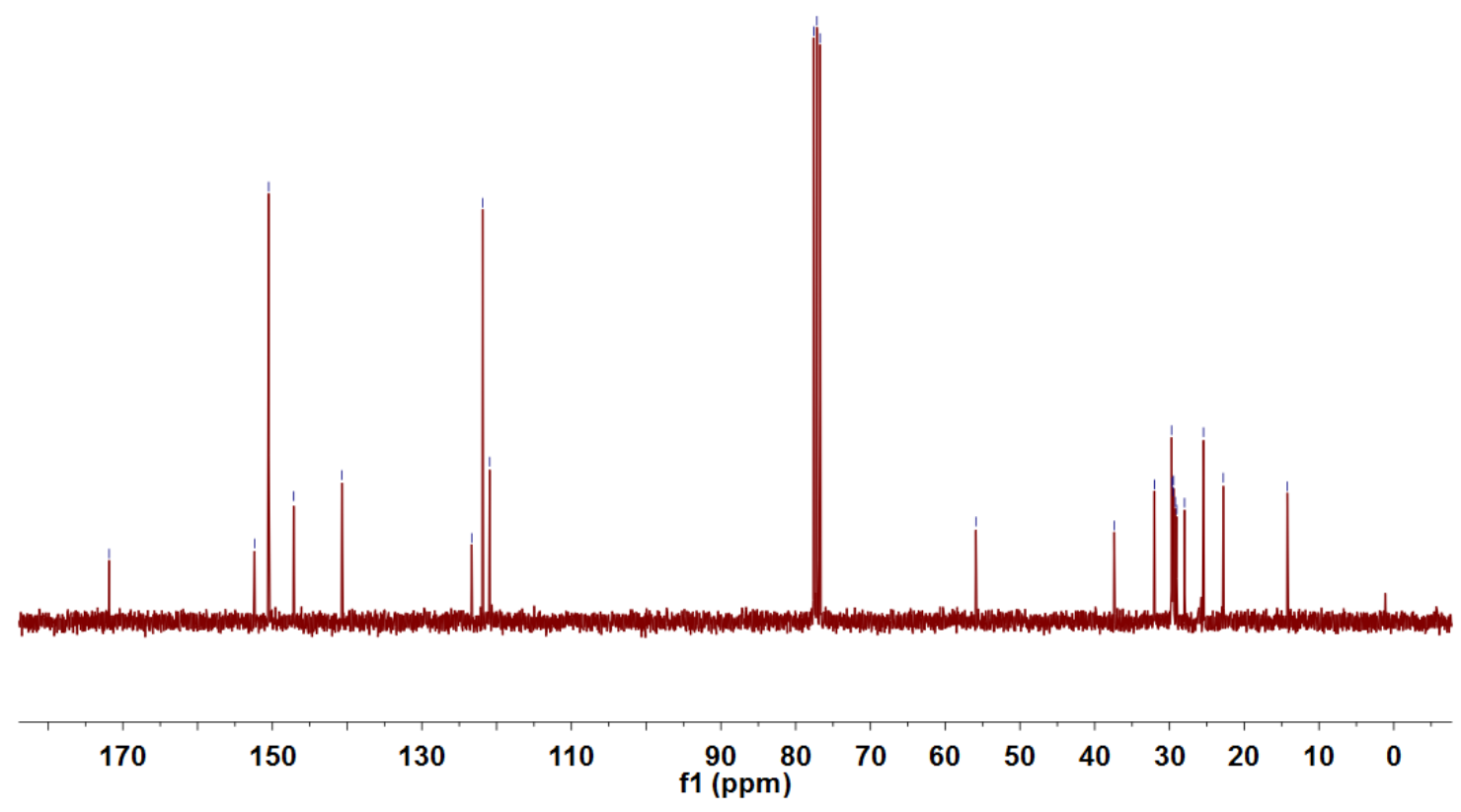

Figure S8. ${ }^{13} \mathrm{C}$ NMR spectrum $\left(100 \mathrm{MHz}, \mathrm{CDCl}_{3}, 293 \mathrm{~K}\right)$ of $\mathbf{1}$. 


\subsection{Synthesis of PBEMA-b-POEGMA}

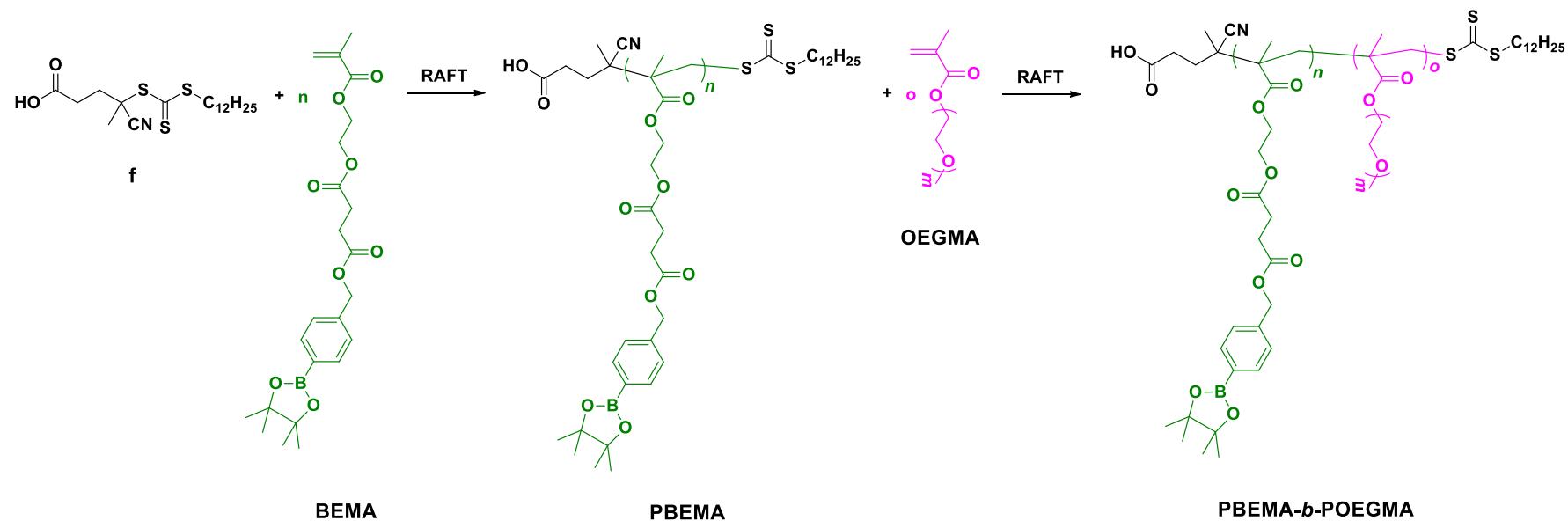

Scheme S4. Synthetic route to PBEMA-b-POEGMA.

Synthesis of PBEMA: Reversible addition-fragmentation chain transfer (RAFT) polymerization technique was employed for the synthesis of PBEMA. Compound $\mathbf{f}(0.100 \mathrm{mmol})$, BEMA (4.00 mmol), and AIBN (0.002 mmol) were charged into a glass ampoule containing $3 \mathrm{~mL}$ of acetone. The ampoule was then degassed via three freeze-pump-thaw cycles and flame-sealed under vacuum. It was then immersed into an oil bath at $60{ }^{\circ} \mathrm{C}$ to start the polymerization. After $12 \mathrm{~h}$, the ampoule was quenched into liquid nitrogen to terminate the polymerization. The mixture was precipitated into an excess of diethyl ether to generate pale residues, the residues were dissolved in DCM and precipitated into diethyl ether. The final product was dried in a vacuum oven overnight at room temperature, yielding a light yellow oil. The polymerization degree of the PBEMA segment was calculated to be 28 by comparing the integration ratio between the protons on compound $\mathbf{f}$ and PBEMA.

Synthesis of PBEMA- $\boldsymbol{b}$-POEGMA: Reversible addition-fragmentation chain transfer (RAFT) polymerization technique was employed for the synthesis of PBEMA- $\boldsymbol{b}$-POEGMA by using PBEMA as a macromolecular initiator. PBEMA $(40.0 \mu \mathrm{mol})$, OEGMA $(1.60 \mathrm{mmol})$, and AIBN (4.00 $\mu \mathrm{mol})$ were charged into a glass ampoule containing $6 \mathrm{~mL}$ acetone. The ampoule was then degassed via three freeze-pump-thaw cycles and flame-sealed under vacuum. It was then immersed into an oil bath at $60{ }^{\circ} \mathrm{C}$ to start the polymerization. After $8 \mathrm{~h}$, the ampoule was quenched into liquid nitrogen to terminate the polymerization. The mixture was precipitated into an excess of diethyl ether to generate pale residues, the residues were dissolved in DCM and precipitated into diethyl ether. The final product was dried in a vacuum oven overnight at room temperature, yielding a light yellow oil. The polymerization degree of the POEGMA segment was calculated to be 24 by comparing the integration ratio between the peaks related to the protons on POEGMA and PBEMA. 


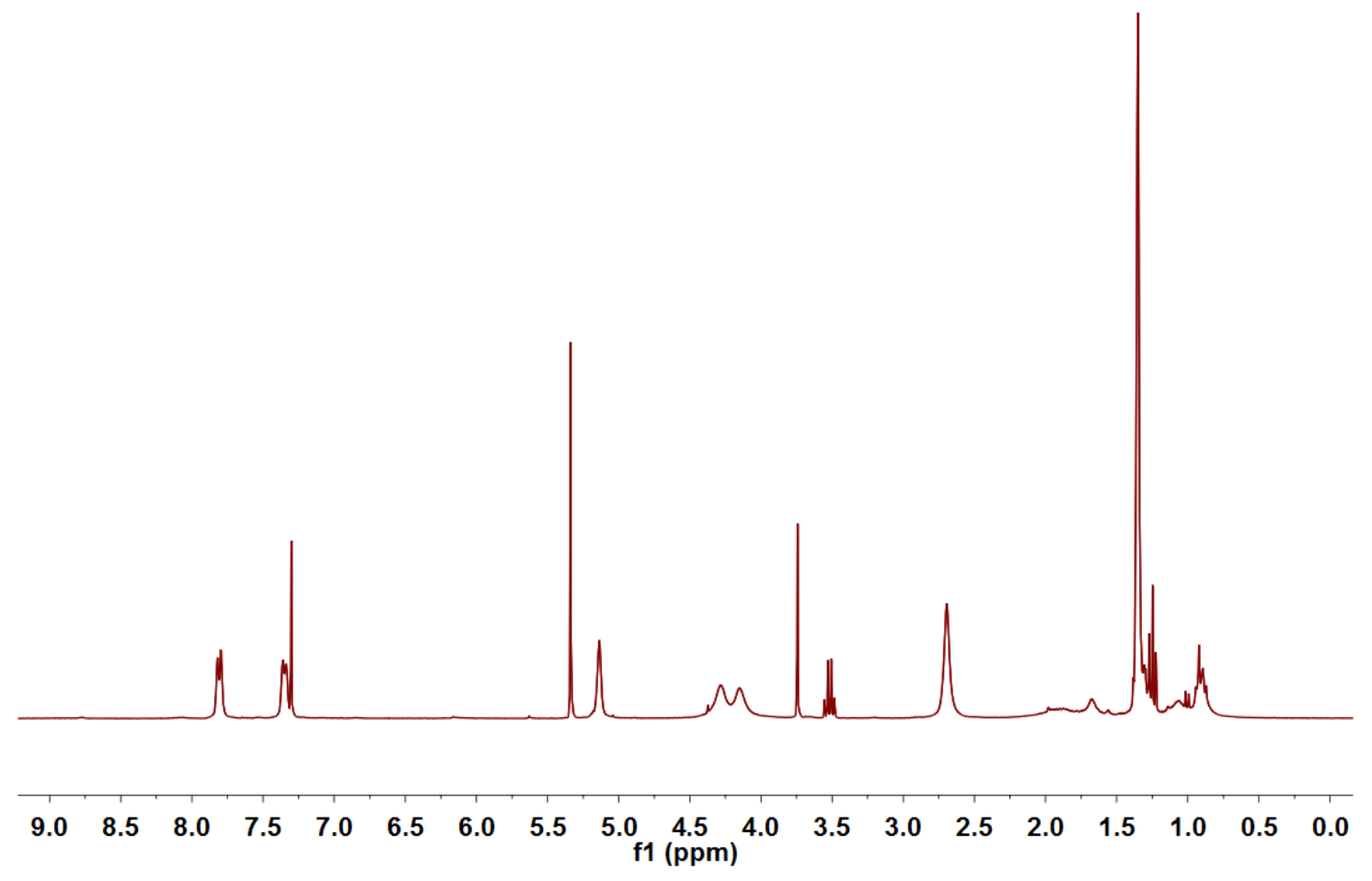

Figure S9. ${ }^{1} \mathrm{H}$ NMR spectrum (400 MHz, $\mathrm{CDCl}_{3}, 293 \mathrm{~K}$ ) of PBEMA-b-POEGMA.

\subsection{Synthesis of PBrEMA-b-POEGMA}

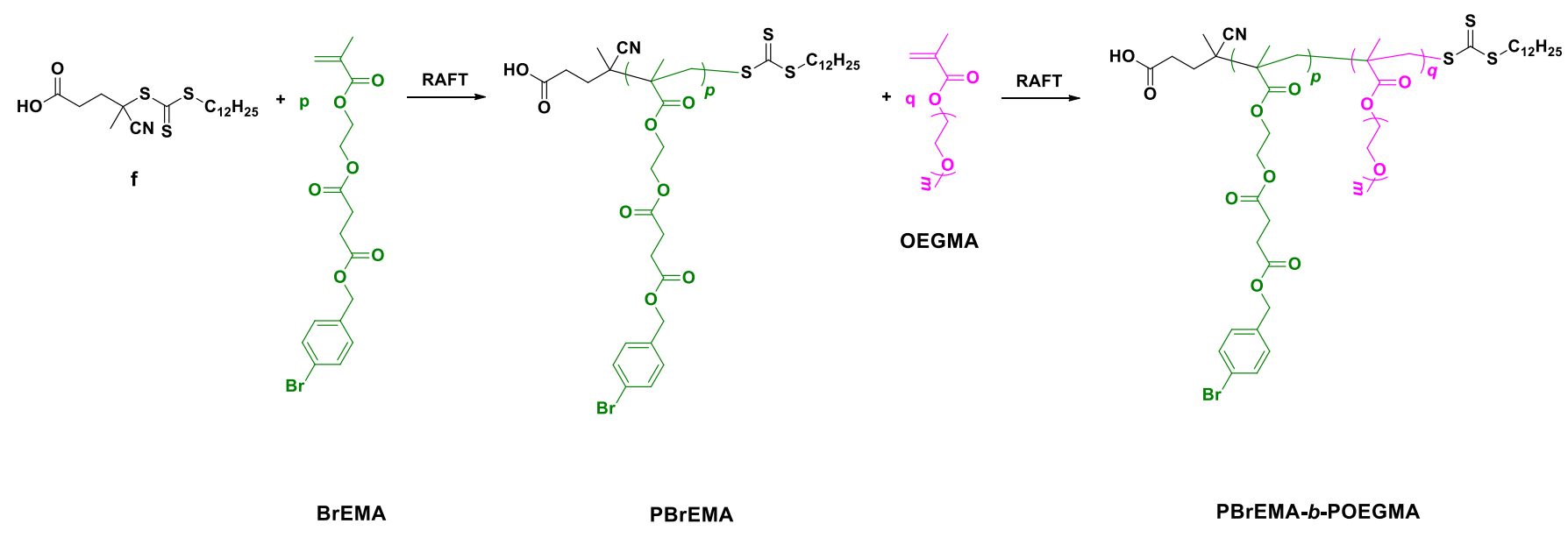

Scheme S5. Synthetic route to PBrEMA-b-POEGMA.

Synthesis of PBrEMA: Reversible addition-fragmentation chain transfer (RAFT) polymerization technique was employed for the synthesis of PBrEMA. f (0.100 mmol), BrEMA (4.00 mmol), and AIBN $(10.0 \mu \mathrm{mol})$ were charged into a glass ampoule containing $3 \mathrm{~mL}$ acetone. The ampoule was then degassed via three freeze-pump-thaw cycles and flame-sealed under vacuum. It was then immersed into an oil bath at $60{ }^{\circ} \mathrm{C}$ to start the polymerization. After $12 \mathrm{~h}$, the ampoule was quenched into liquid nitrogen to terminate the polymerization. The mixture was precipitated into an excess of diethyl ether to generate 
pale residues, the residues were dissolved in DCM and precipitated into diethyl ether. The final product was dried in a vacuum oven overnight at room temperature, yielding a white powder. The polymerization degree of the PBrEMA segment was calculated to be 25 by comparing the integration ratio between the protons on compound $\mathbf{f}$ and PBrEMA.

Synthesis of PBrEMA- $\boldsymbol{b}$-POEGMA: Reversible addition-fragmentation chain transfer (RAFT) polymerization technique was employed for the synthesis of PBrEMA- $\boldsymbol{b}$-POEGMA by using PBrEMA as a macromolecular initiator. PBrEMA $(50.0 \mu \mathrm{mol})$, OEGMA $(2.00 \mathrm{mmol})$, and AIBN (5.00 $\mu \mathrm{mol})$ were charged into a glass ampoule containing $4 \mathrm{~mL}$ acetone. The ampoule was then degassed via three freeze-pump-thaw cycles and flame-sealed under vacuum. It was then immersed into an oil bath at $60{ }^{\circ} \mathrm{C}$ to start the polymerization. After $8 \mathrm{~h}$, the ampoule was quenched into liquid nitrogen to terminate the polymerization. The mixture was precipitated into an excess of diethyl ether to generate pale residues, the residues were dissolved in DCM and precipitated into diethyl ether. The final product was dried in a vacuum oven overnight at room temperature, yielding a sticky solid. The polymerization degree of the POEGMA segment was calculated to be 26 by comparing the integration ratio between the peaks related to the protons on POEGMA and PBEMA.

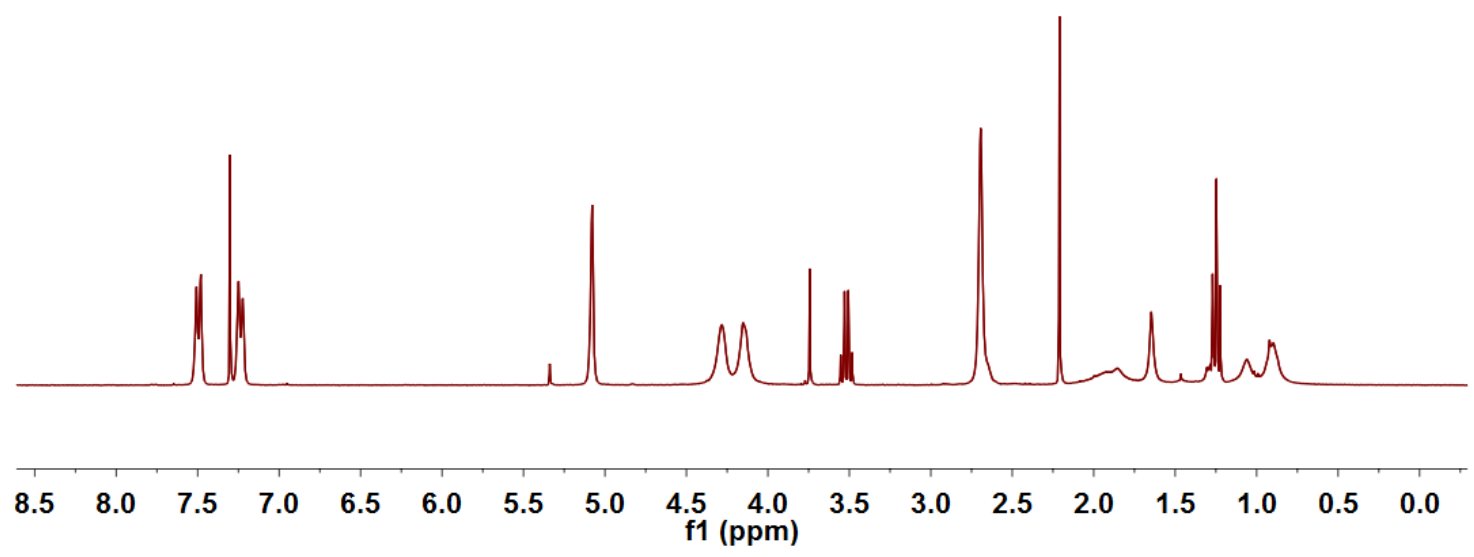

Figure S10. ${ }^{1} \mathrm{H}$ NMR spectrum (400 MHz, $\mathrm{CDCl}_{3}, 293 \mathrm{~K}$ ) of PBrEMA-b-POEGMA. 
2.6. Synthesis of hexagonal metallacycle 3
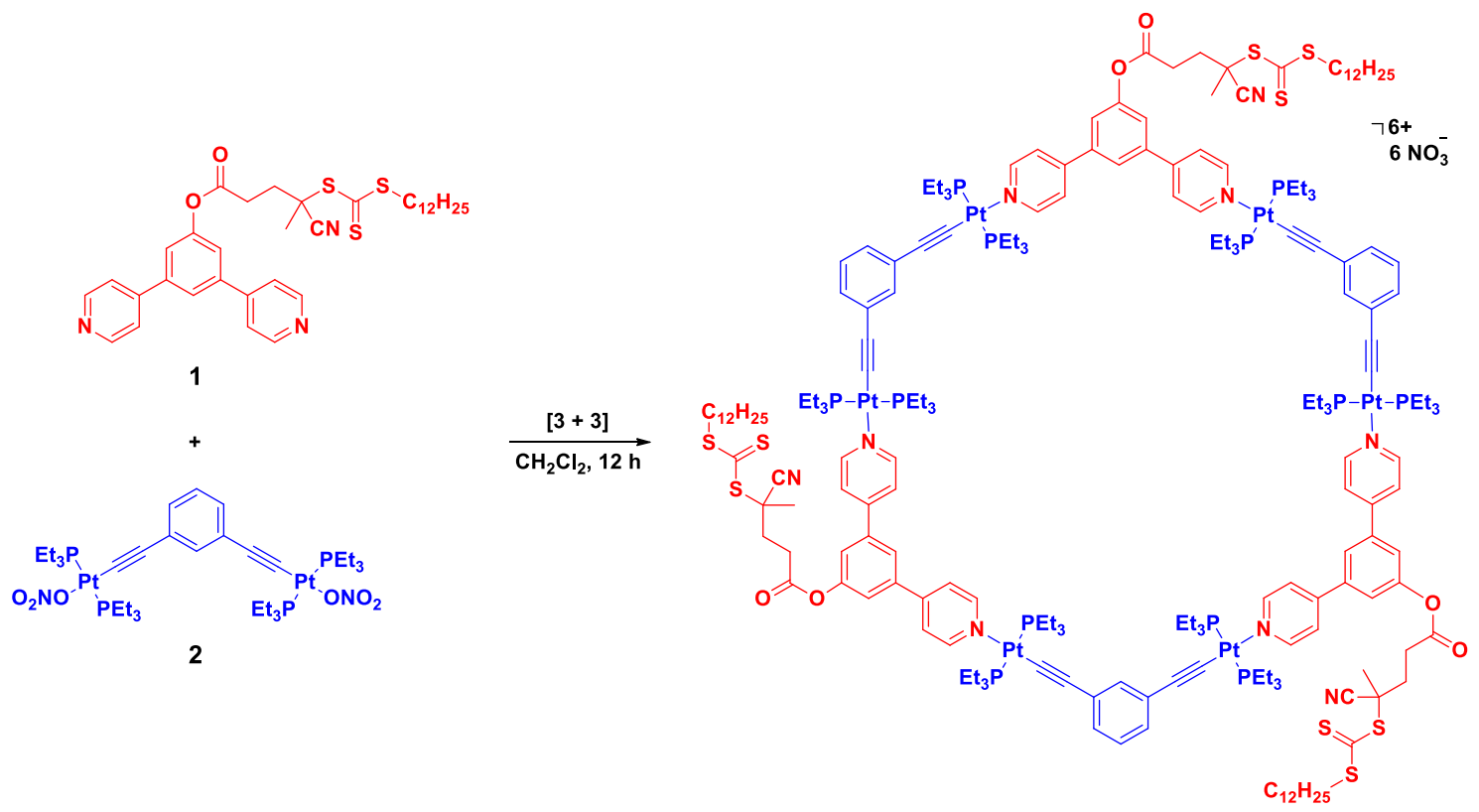

3

Scheme S6. Synthetic route to 3 .

Compounds 1 (12.7 mg, $20.0 \mathrm{mmol})$ and $2(22.2 \mathrm{mg}, 20.0 \mathrm{mmol})$ were placed into a $20 \mathrm{~mL}$ pressure tube charged with a small stir bar. About $5 \mathrm{~mL}$ of $\mathrm{CH}_{2} \mathrm{Cl}_{2}$ was added, and the tube was sealed followed by stirring at room temperature for $12 \mathrm{~h}$. The solvent was removed under vacuum and concentrated and diethyl ether was slowly added to precipitate product 3 as a light yellow powder $(31.4 \mathrm{mg}, 90 \%)$. The successful preparation of $\mathbf{3}$ was confirmed by ${ }^{1} \mathrm{H}$ NMR (Figure S11) and ${ }^{31} \mathrm{P}\left\{{ }^{1} \mathrm{H}\right\}$ NMR (Figure S12) analyses. 


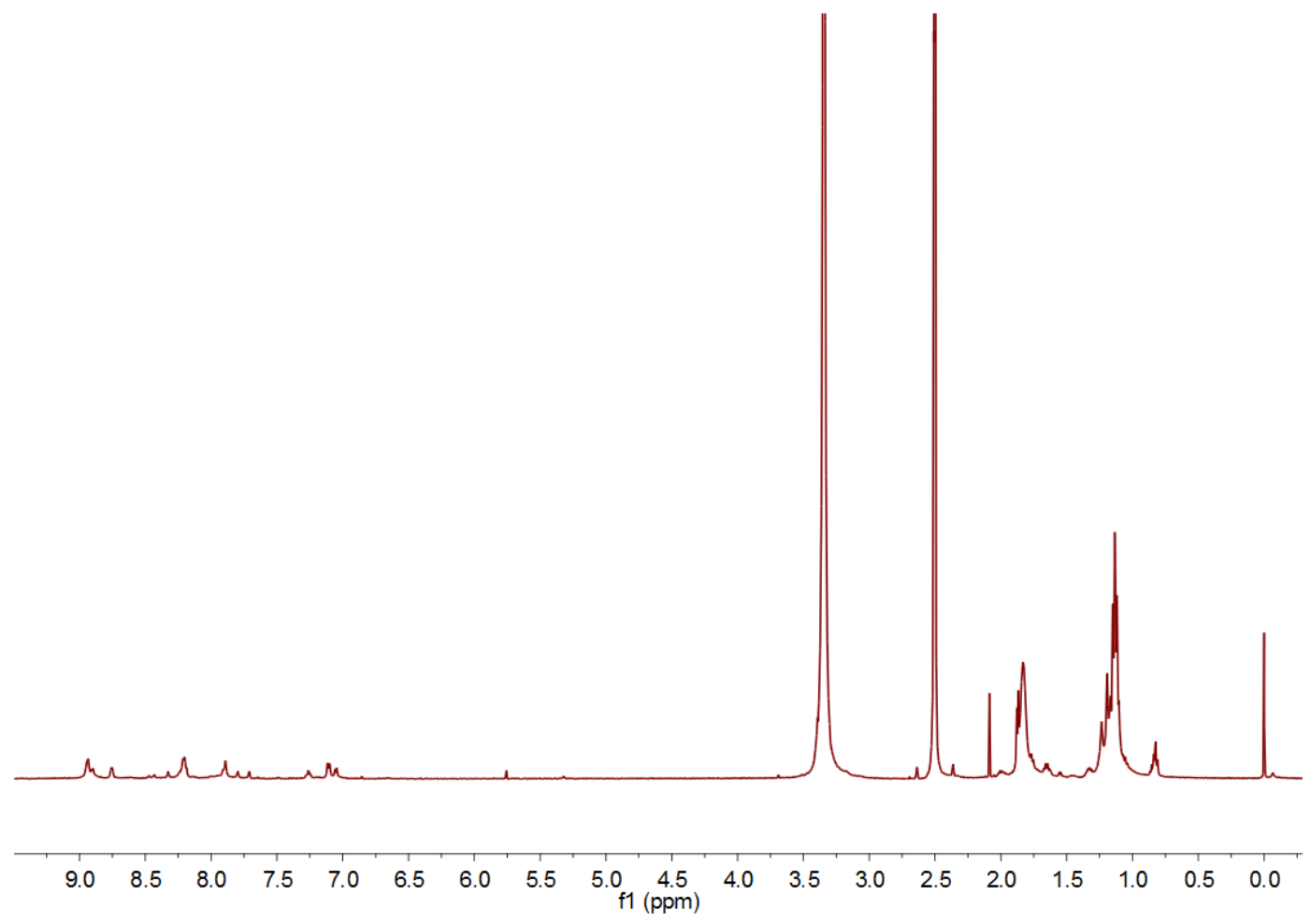

Figure S11. ${ }^{1} \mathrm{H}$ NMR spectrum (400 MHz, DMSO- $d_{6}, 293 \mathrm{~K}$ ) of 3.

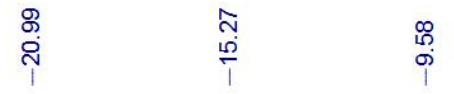

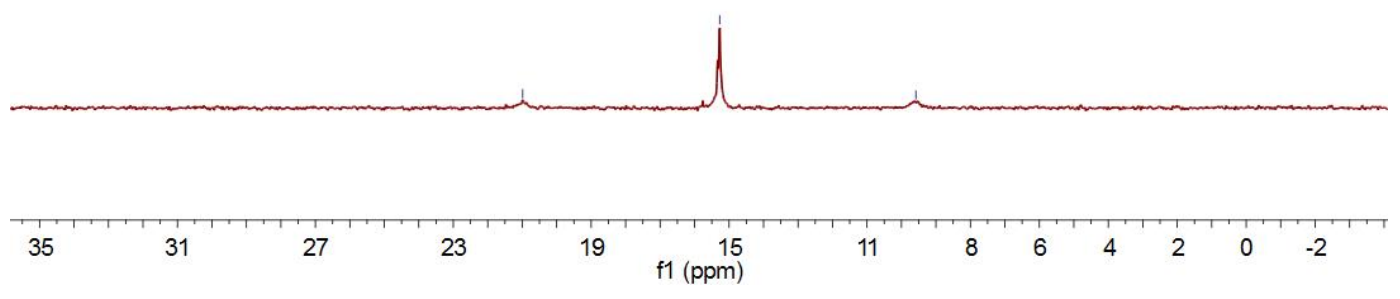

Figure S12. ${ }^{31} \mathrm{P}\left\{{ }^{1} \mathrm{H}\right\}$ NMR spectrum $\left(121.4 \mathrm{MHz}, \mathrm{DMSO}-d_{6}, 293 \mathrm{~K}\right)$ of 3. 


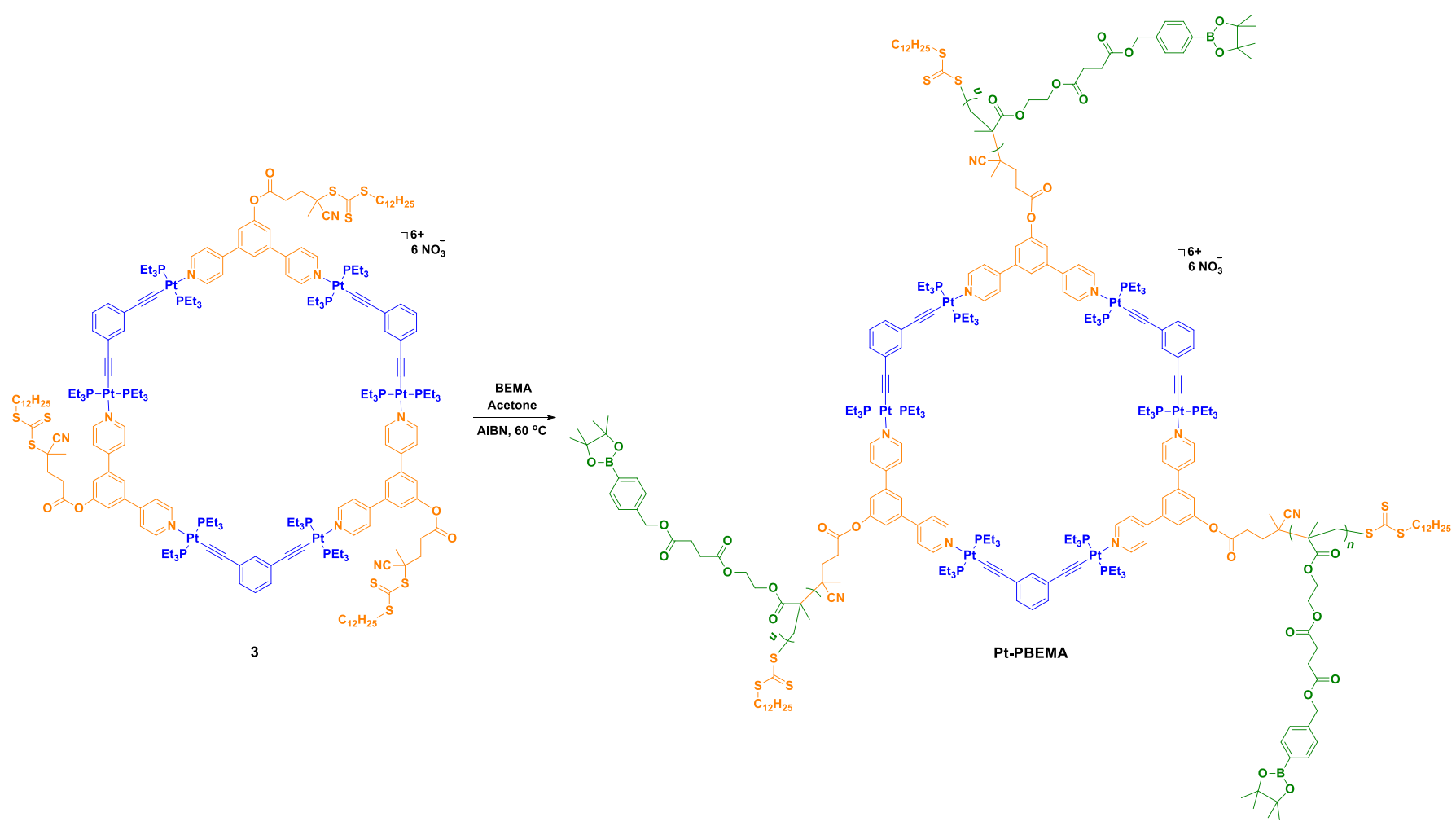

Scheme S7. Synthetic route to Pt-PBEMA.

Supramolecular hexagonal metallacycle $3 \quad(8.00 \mu \mu \mathrm{mol}), \quad$ AIBN $\quad\left(\begin{array}{llll}0.800 & \mu \mathrm{mol}\end{array}\right)$, [2-((((4-(4,4,5,5-tetramethyl-1,3,2-dioxaborolan-2-yl)benzyl)oxy)carbonyl)oxy)ethyl methacrylate] (BEMA) (0.400 mmol), and $1.5 \mathrm{~mL}$ of acetone were added into a $10.0 \mathrm{~mL}$ flask equipped with a magnetic stirring bar. After being degassed by freeze-pump-thaw cycles for three times, the mixed solution was immediately transferred to the preheated oil bath at $60{ }^{\circ} \mathrm{C}$ to initiate the polymerization. After $12 \mathrm{~h}$, the polymerization was quenched by liquid $\mathrm{N}_{2}$, and the resultant mixture was precipitated in diethyl ether. The precipitate was dissolved in acetone and then precipitated again in the presence of cold diethyl ether. The above dissolution-precipitation cycle was repeated three times. The final product was dried in a vacuum oven overnight at room temperature. The polymerization degree of the PBEMA segment was calculated to be 28 by comparing the integration ratio between the peaks related to the protons on compound 3 and PBEMA. 


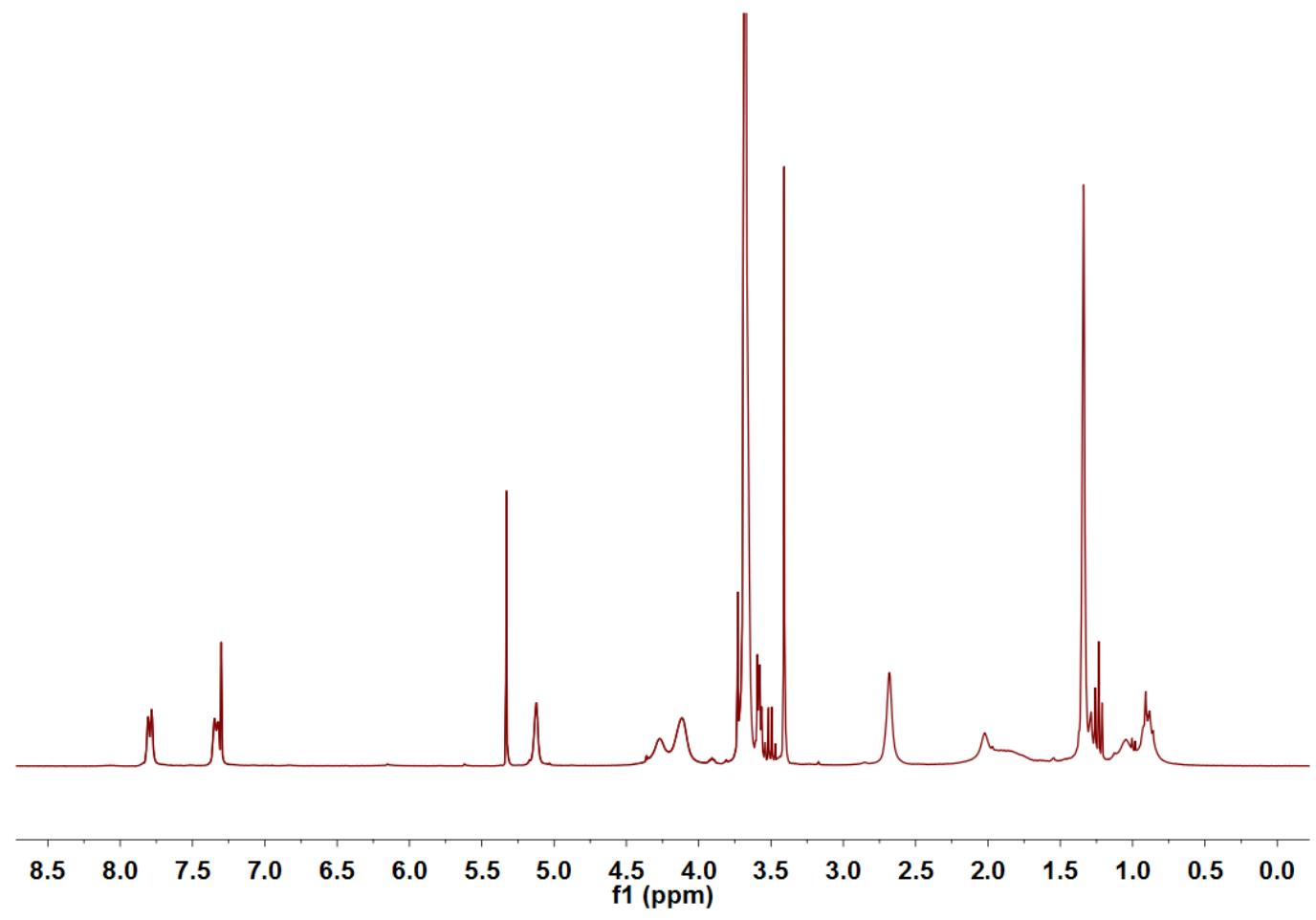

Figure S13. ${ }^{1} \mathrm{H}$ NMR spectrum (400 MHz, acetone- $\left.d_{6}, 293 \mathrm{~K}\right)$ of Pt-PBEMA.

2.8. Synthesis of supramolecular block copolymer Pt-PBEMA-b-POEGMA.

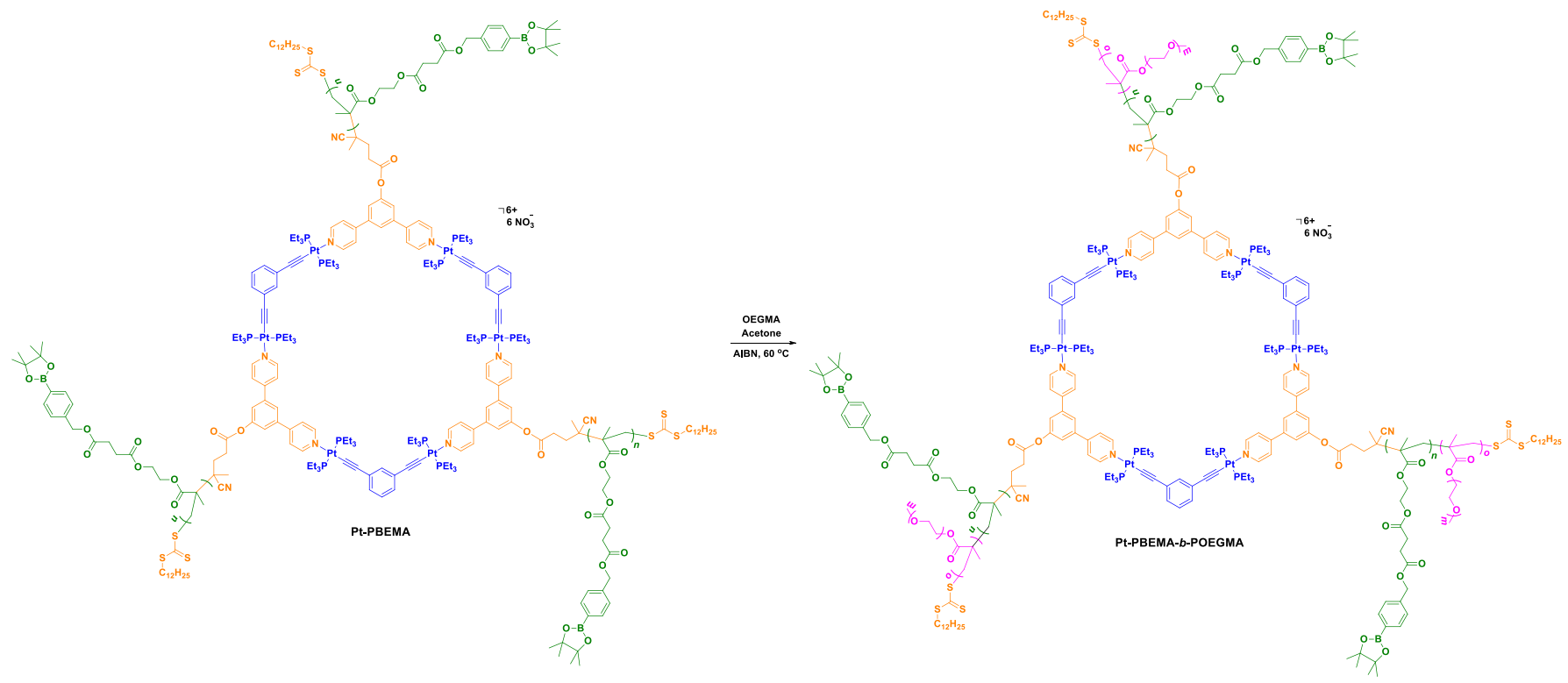

Scheme S8. Synthetic route to Pt-PBEMA-b-POEGMA.

Supramolecular polymer Pt-PBEMA $(5.00 \mu \mathrm{mol})$, AIBN $(0.500 \mu \mathrm{mol})$, OEGMA $(250 \mu \mathrm{mol})$, and $5 \mathrm{~mL}$ of acetone were added into a flask equipped with a magnetic stirring bar. After being degassed by freeze-pump-thaw cycles for three times, the mixed solution was immediately transferred to the preheated oil bath at $60{ }^{\circ} \mathrm{C}$ to initiate the polymerization. After $8 \mathrm{~h}$, the polymerization was quenched by liquid $\mathrm{N}_{2}$, 
and the resultant mixture was precipitated in diethyl ether. The precipitate was dissolved in acetone and then precipitated again in the presence of cold diethyl ether. The above dissolution-precipitation cycle was repeated three times. The final product was dried in a vacuum oven overnight at room temperature, yielding a light yellow oil. The polymerization degree of the POEGMA segment was calculated to be 25 by comparing the integration ratio between the peaks related to the protons on POEGMA and PBEMA.

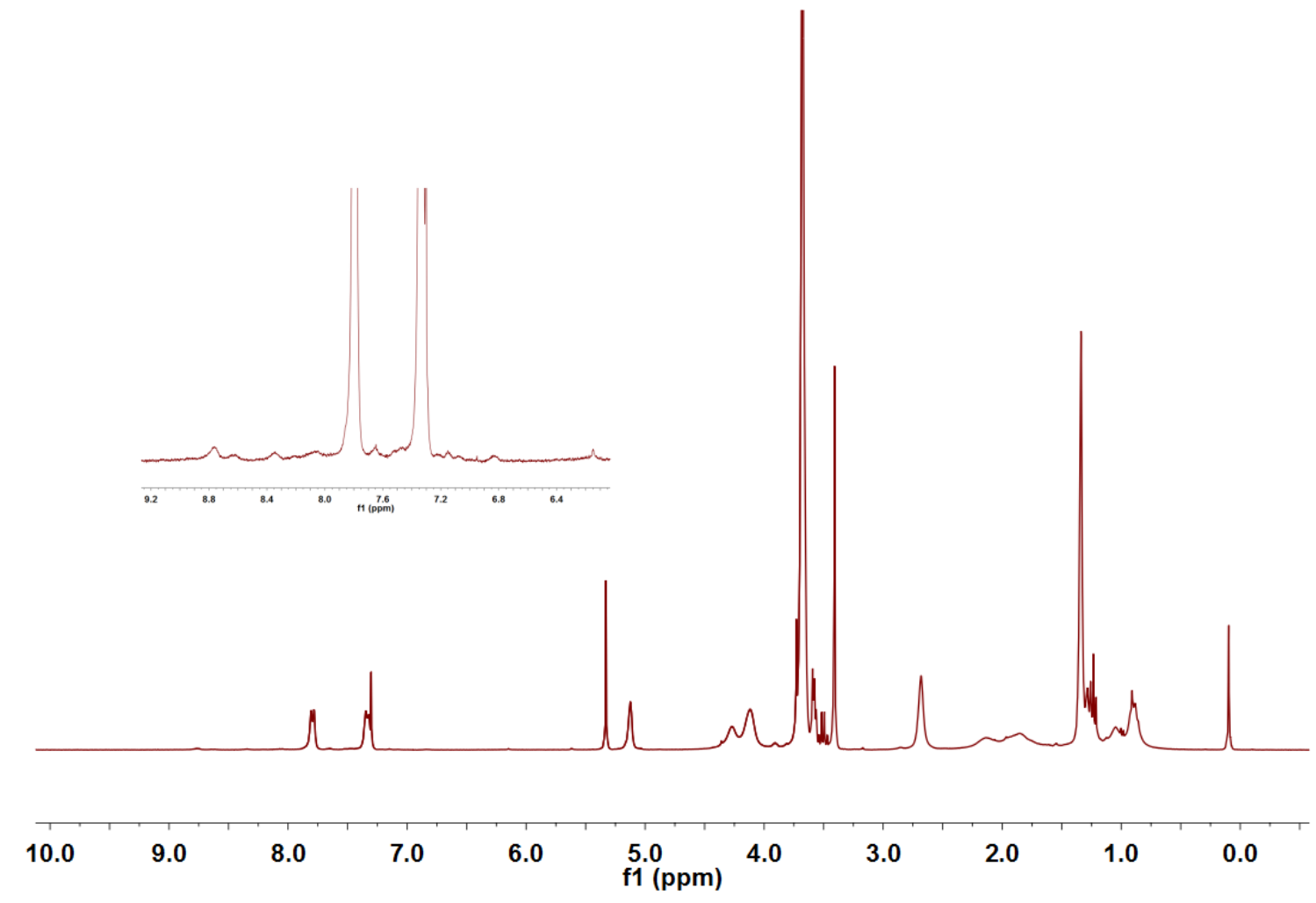

Figure S14. ${ }^{1} \mathrm{H}$ NMR spectrum (400 MHz, $\mathrm{CDCl}_{3}, 293 \mathrm{~K}$ ) of Pt-PBEMA-b-POEGMA. 


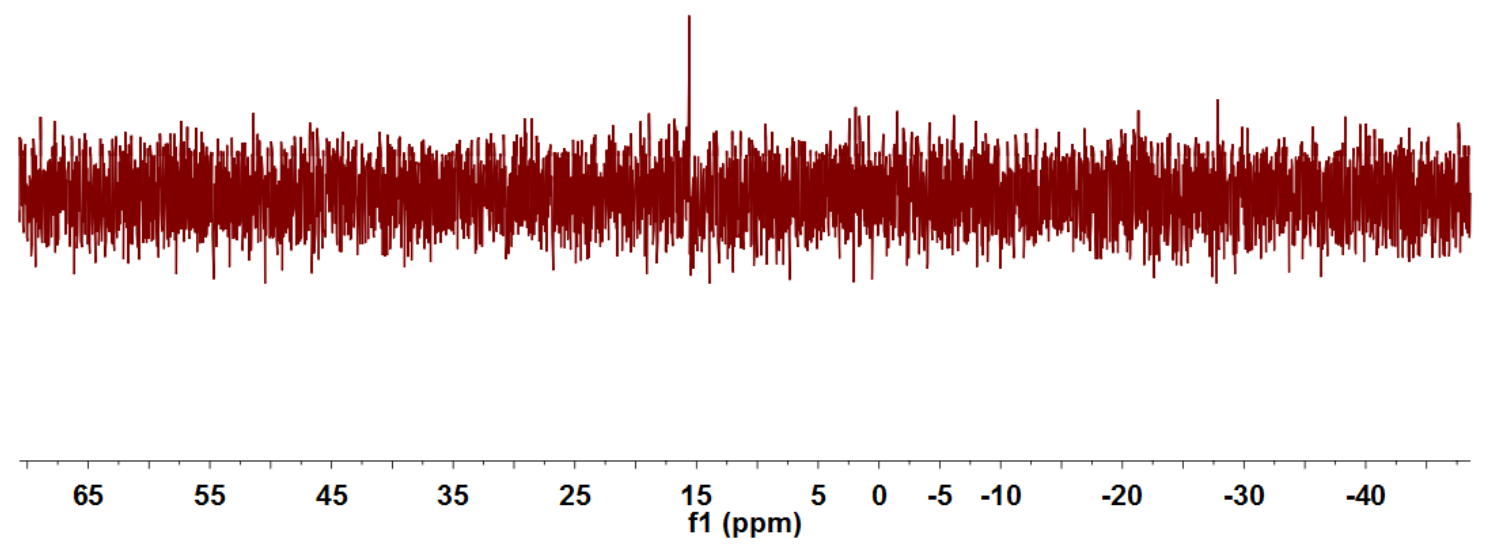

Figure S15. ${ }^{31} \mathrm{P}\left\{{ }^{1} \mathrm{H}\right\}$ NMR spectrum (121.4 MHz, $\left.\mathrm{CDCl}_{3}, 293 \mathrm{~K}\right)$ of Pt-PBEMA-b-POEGMA.

2.9. Synthesis of supramolecular polymer Pt-PBrEMA.

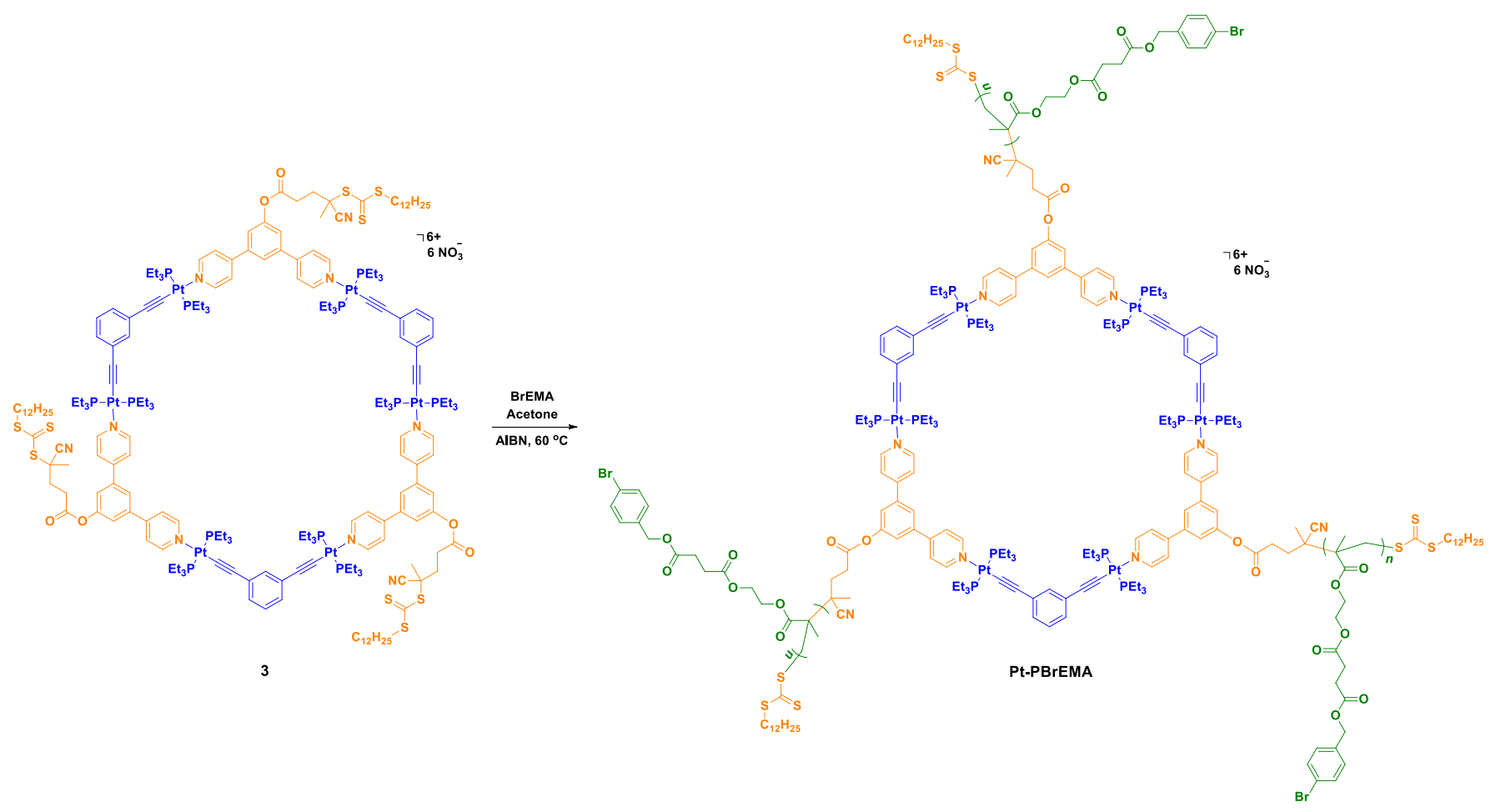

Scheme S9. Synthetic route to Pt-PBrEMA. 
Supramolecular hexagonal metallacycle $3(10.0 \mu \mathrm{mol})$, AIBN (1.00 $\mu \mathrm{mol})$, BrEMA $(0.400 \mathrm{mmol})$, and 2 $\mathrm{mL}$ of acetone were added into a $10.0 \mathrm{~mL}$ flask equipped with a magnetic stirring bar. After being degassed by freeze-pump-thaw cycles for three times, the mixed solution was immediately transferred to the preheated oil bath at $60{ }^{\circ} \mathrm{C}$ to initiate the polymerization. After $12 \mathrm{~h}$, the polymerization was quenched by liquid $\mathrm{N}_{2}$, and the resultant mixture was precipitated in diethyl ether. The precipitate was dissolved in acetone and then precipitated again in the presence of cold diethyl ether. The above dissolution-precipitation cycle was repeated three times. The final product was dried in a vacuum oven overnight at room temperature, yielding a white solid powder. The polymerization degree of the PBrEMA segment was calculated to be 23 by comparing the integration ratio between the peaks related to the protons on compound 3 and PBrEMA.

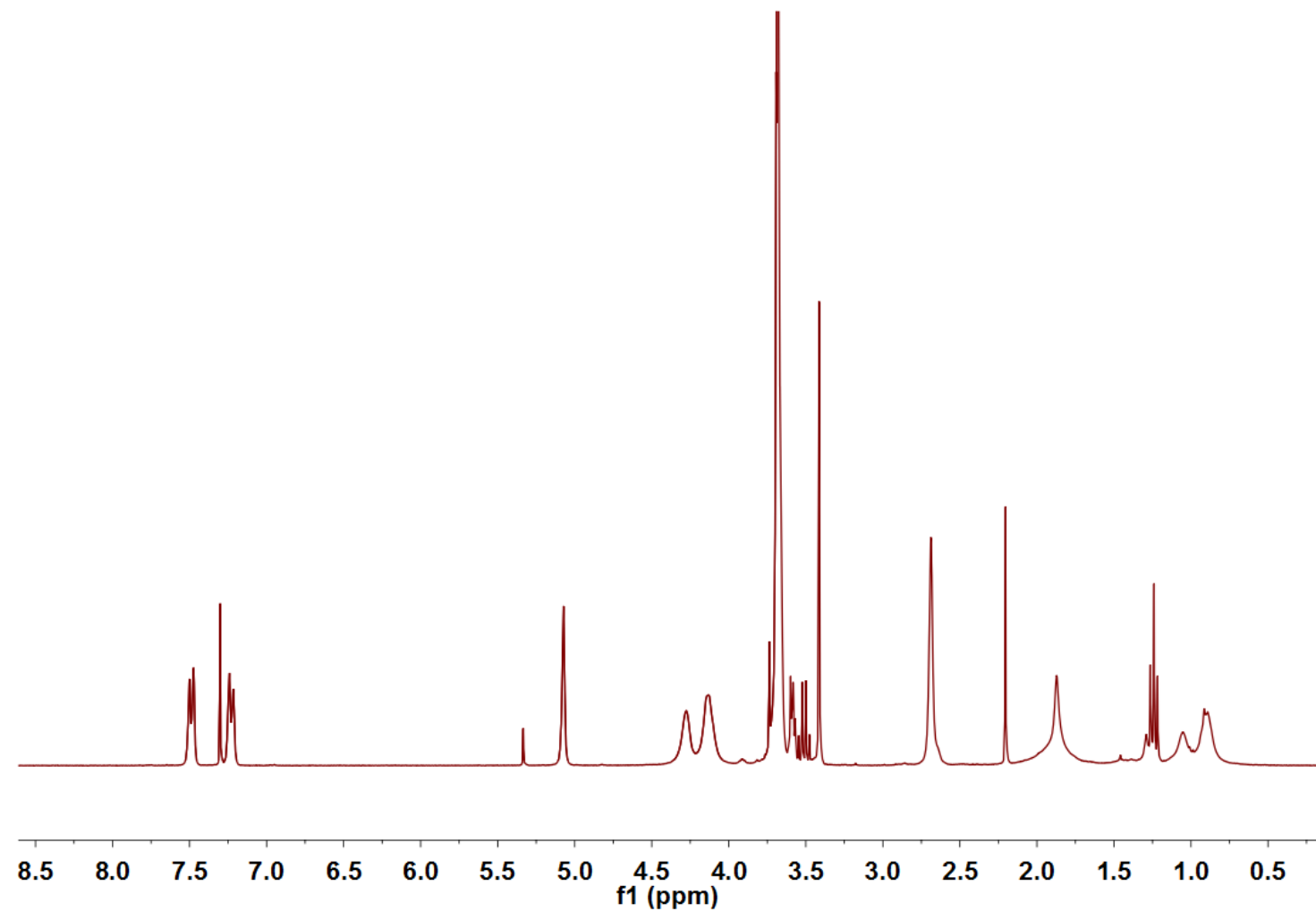

Figure S16. ${ }^{1} \mathrm{H}$ NMR spectrum (400 MHz, acetone- $\left.d_{6}, 293 \mathrm{~K}\right)$ of Pt-PBrEMA. 


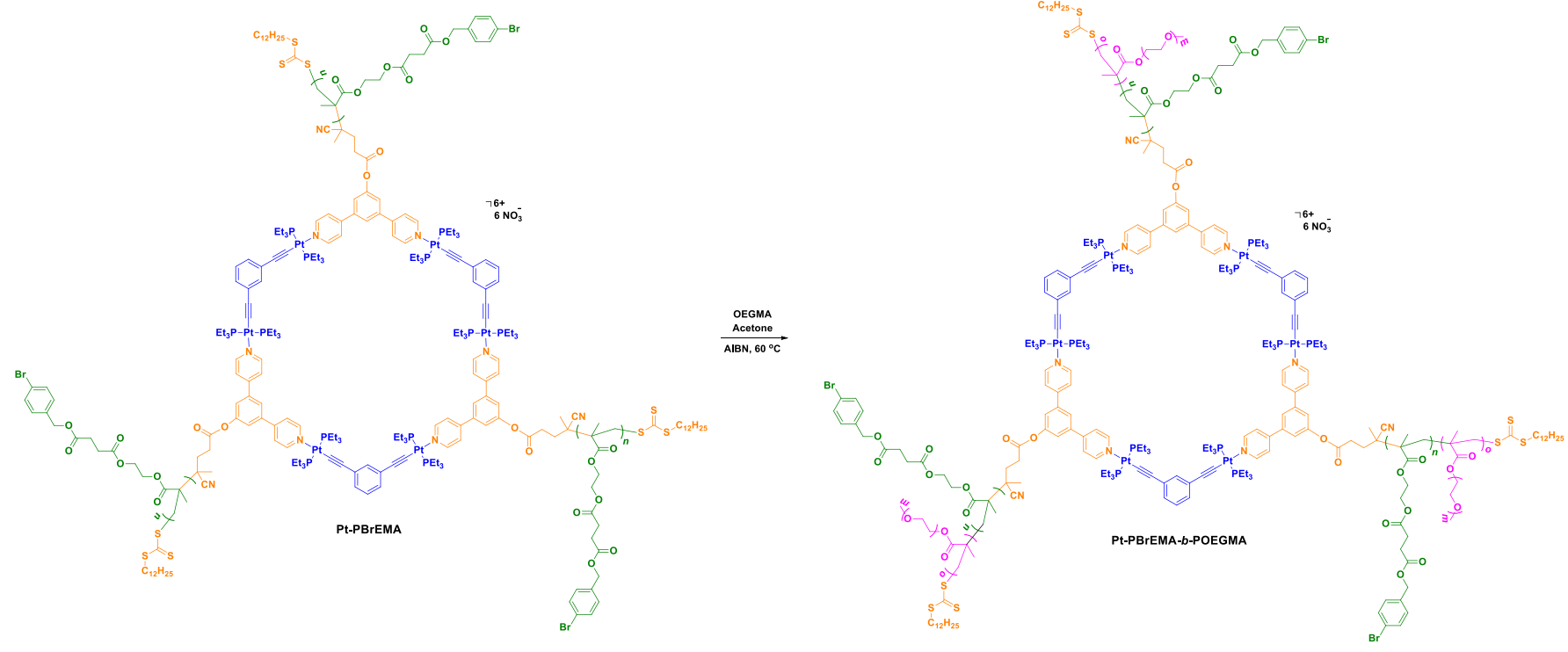

Scheme S10. Synthetic route to Pt-PBrEMA-b-POEGMA.

Supramolecular polymer Pt-PBrEMA $(5.00 \mu \mathrm{mol})$, AIBN $(0.500 \mu \mathrm{mol})$, OEGMA (250 $\mu \mathrm{mol})$, and $6 \mathrm{~mL}$ of acetone were added into a flask equipped with a magnetic stirring bar. After being degassed by freeze-pump-thaw cycles for three times, the mixed solution was immediately transferred to the preheated oil bath at $60{ }^{\circ} \mathrm{C}$ to initiate the polymerization. After $8 \mathrm{~h}$, the polymerization was quenched by liquid $\mathrm{N}_{2}$, and the resultant mixture was precipitated in diethyl ether. The precipitate was dissolved in acetone and then precipitated again in the presence of cold diethyl ether. The above dissolution-precipitation cycle was repeated three times. The final product was dried in a vacuum oven overnight at room temperature, yielding a sticky solid. The polymerization degree of the POEGMA segment was calculated to be 27 by comparing the integration ratio between the peaks related to the protons on POEGMA and PBrEMA. 


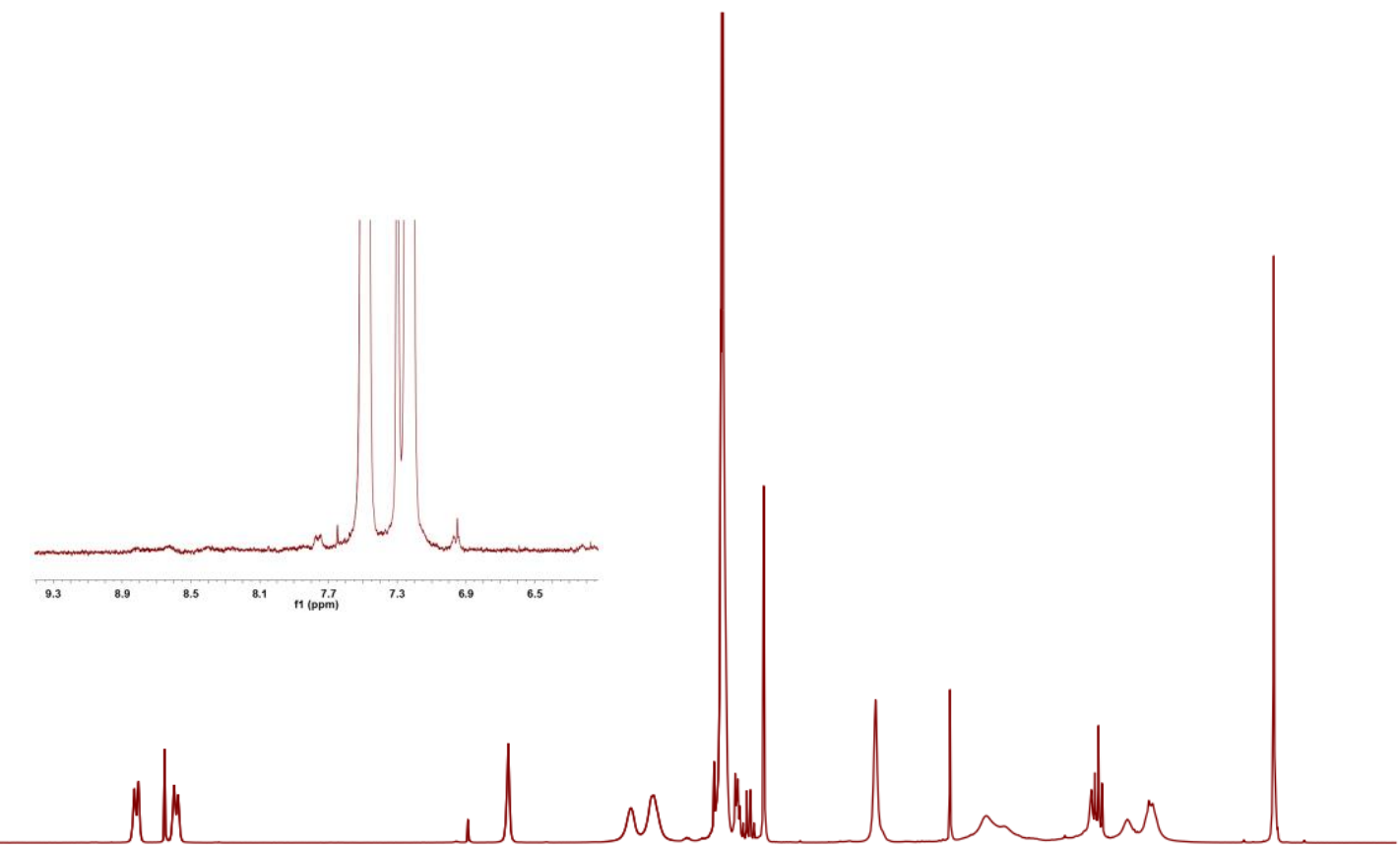

$\begin{array}{llllllllllllllllll}8.5 & 8.0 & 7.5 & 7.0 & 6.5 & 6.0 & 5.5 & 5.0 & 4.5 & 4.0 & 3.5 & 3.0 & 2.5 & 2.0 & 1.5 & 1.0 & 0.5 & 0.0\end{array}$

Figure S17. ${ }^{1} \mathrm{H}$ NMR spectrum (400 MHz, $\mathrm{CDCl}_{3}, 293 \mathrm{~K}$ ) of Pt-PBrEMA-b-POEGMA. 


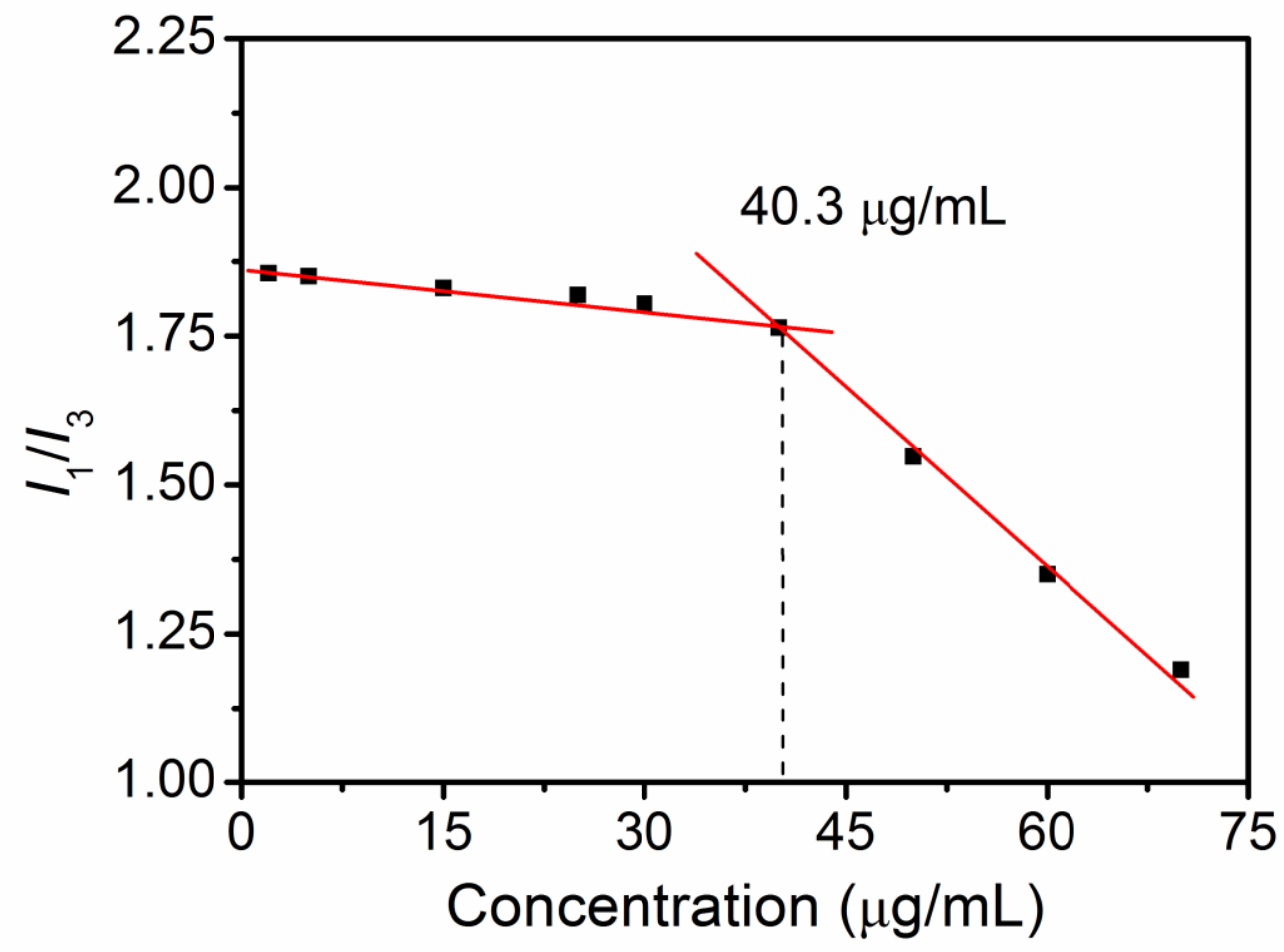

Figure S18. CAC value determination of PBEMA-b-POEGMA by using pyrene as a probe.

Table S1. Drug Loading Capability and Stability Evaluations of $\mathrm{H}_{2} \mathrm{O}_{2}$-Responsive Pt NPs.

\begin{tabular}{|c|c|c|c|c|c|c|}
\hline & $\begin{array}{l}\text { Polymer } \\
\text { (mg) }\end{array}$ & $\begin{array}{l}\text { Cargo } \\
\text { (mg) }\end{array}$ & $\begin{array}{l}\text { LE } \\
(\%)^{\mathrm{a}}\end{array}$ & $\begin{array}{l}\mathrm{LC} \\
(\%)^{b}\end{array}$ & $\begin{array}{l}\text { Size } \\
(\mathbf{n m})^{\mathrm{c}}\end{array}$ & Stability \\
\hline \multirow{5}{*}{ PA } & 100 & 20 & 98.4 & 16.4 & $89.4 \pm 12.4$ & No precipitation over $1 \mathrm{~d}$ \\
\hline & 100 & 40 & 95.7 & 27.6 & $98.7 \pm 11.2$ & No precipitation over $1 \mathrm{~d}$ \\
\hline & 100 & 60 & 88.5 & 34.7 & $134 \pm 10.7$ & No precipitation over $1 \mathrm{~d}$ \\
\hline & 100 & 80 & 79.6 & 38.9 & $186 \pm 22.5$ & Precipitation within $8 \mathrm{~h}$ \\
\hline & 100 & 100 & 70.2 & 41.1 & $227 \pm 17.3$ & Precipitation within $2 \mathrm{~h}$ \\
\hline \multirow{5}{*}{ DOX } & 100 & 20 & 95.1 & 15.9 & $82.5 \pm 7.6$ & No precipitation over $1 \mathrm{~d}$ \\
\hline & 100 & 40 & 92.7 & 27.1 & $94.6 \pm 11.3$ & No precipitation over $1 \mathrm{~d}$ \\
\hline & 100 & 60 & 82.8 & 33.3 & $127 \pm 13.4$ & No precipitation over $1 \mathrm{~d}$ \\
\hline & 100 & 80 & 77.6 & 38.3 & $248 \pm 16.6$ & Precipitation within $4 \mathrm{~h}$ \\
\hline & 100 & 100 & 67.9 & 40.4 & $274 \pm 24.1$ & Precipitation within $2 \mathrm{~h}$ \\
\hline
\end{tabular}

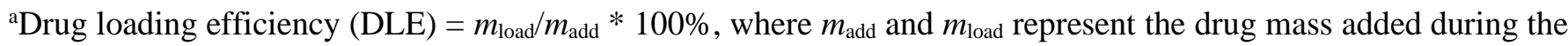
preparation of drug-loaded Pt NPs and loaded by the Pt NPs, respectively.

${ }^{\mathrm{b}}$ Drug loading content $(\mathrm{DLC})=m_{\mathrm{load}}\left(m_{\mathrm{load}}+m\right) * 100 \%$, where $m$ represents the polymer mass used during the preparation of drug-loaded Pt NPs.

'The size of the drug-loaded Pt NPs was measured by DLS. 
Table S2. Drug Loading Capability and Stability Evaluations of Non-Responsive $n \mathbf{P t}$ NPs.

\begin{tabular}{ccccccc}
\hline & $\begin{array}{c}\text { Polymer } \\
(\mathbf{m g})\end{array}$ & $\begin{array}{c}\text { Cargo } \\
(\mathbf{m g})\end{array}$ & $\begin{array}{c}\text { LE } \\
(\mathbf{\%})^{\mathbf{a}}\end{array}$ & $\begin{array}{c}\text { LC } \\
(\mathbf{\%})^{\mathbf{b}}\end{array}$ & $\begin{array}{c}\text { Size } \\
(\mathbf{n m})^{\mathbf{c}}\end{array}$ & Stability \\
\hline \multirow{3}{*}{ PA } & 100 & 20 & 97.3 & 16.3 & $94.8 \pm 8.7$ & No precipitation over 1 d \\
& 100 & 40 & 95.6 & 27.7 & $110 \pm 13.6$ & No precipitation over 1 d \\
& 100 & 60 & 86.5 & 34.3 & $143 \pm 16.0$ & No precipitation over 1 d \\
& 100 & 80 & 73.7 & 37.1 & $211 \pm 17.3$ & Precipitation within 8 h \\
\hline & 100 & 100 & 72.1 & 41.9 & $264 \pm 20.7$ & Precipitation within 2 h \\
\hline \multirow{3}{*}{ DOX } & 100 & 20 & 96.2 & 16.1 & $97.3 \pm 11.2$ & No precipitation over 1 d \\
& 100 & 40 & 90.8 & 26.6 & $115 \pm 14.6$ & No precipitation over 1 d \\
& 100 & 60 & 85.4 & 33.9 & $164 \pm 15.5$ & No precipitation over 1 d \\
& 100 & 80 & 74.9 & 37.5 & $236 \pm 16.7$ & Precipitation within 4 h \\
\hline
\end{tabular}

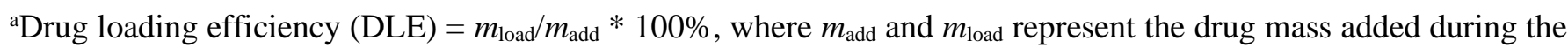
preparation of drug-loaded $n \mathbf{P t}$ NPs and the mass loaded by the $n \mathbf{P t}$ NPs, respectively.

${ }^{\mathrm{b}}$ Drug loading content $(\mathrm{DLC})=m_{\mathrm{load}} /\left(m_{\mathrm{load}}+m\right) * 100 \%$, where $m$ represents the polymer mass used during the preparation of drug-loaded $n \mathbf{P t}$ NPs.

${ }^{\mathrm{c}}$ The size of the drug-loaded $n \mathbf{P t}$ NPs was measured by DLS.

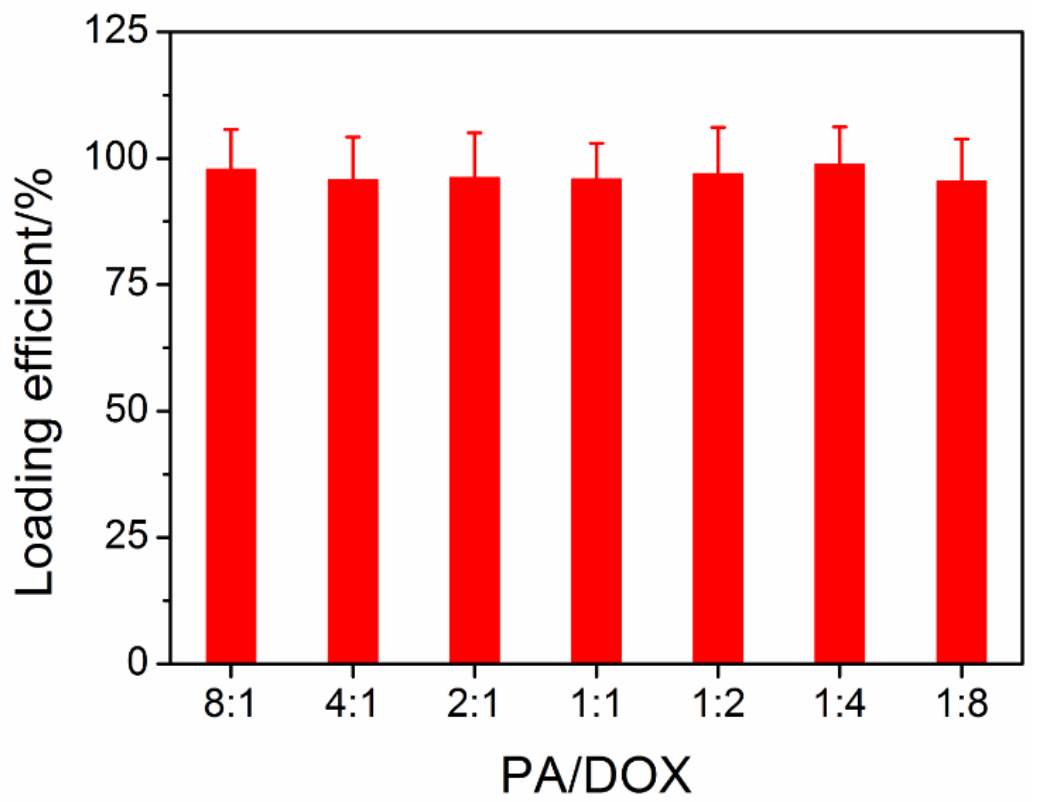

Figure S19. Loading efficiency of Pt NPs with different ratios of PA/DOX. The mass of Pt-PBEMA- $b$-POEGMA was fixed to be $100 \mathrm{mg}$ and the mass of PA/DOX mixture was $40 \mathrm{mg}$ during the preparation of these nanoparticles. 


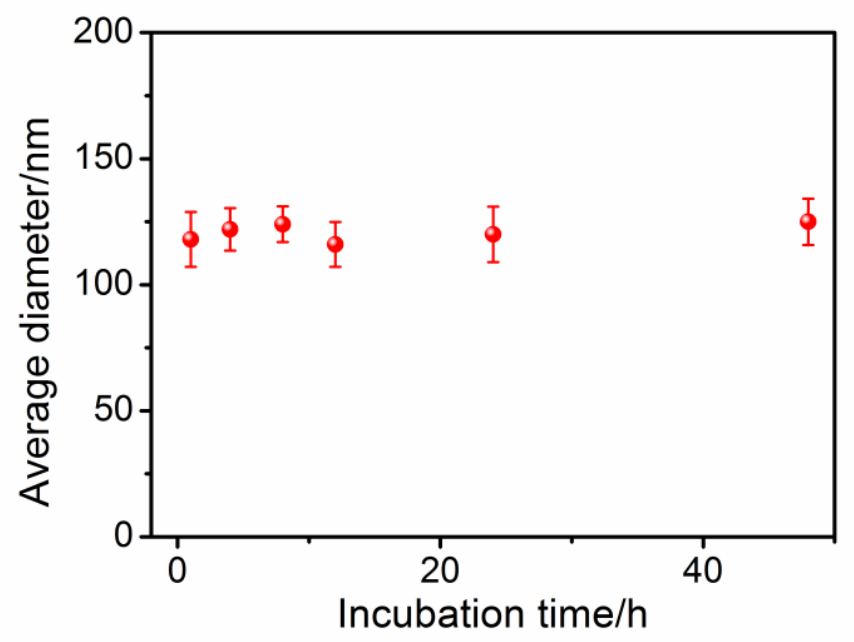

Figure S20. The average diameters of Pt NPs@PA/DOX determined by DLS tests in PBS containing 10\% FBS after different time periods of incubation.
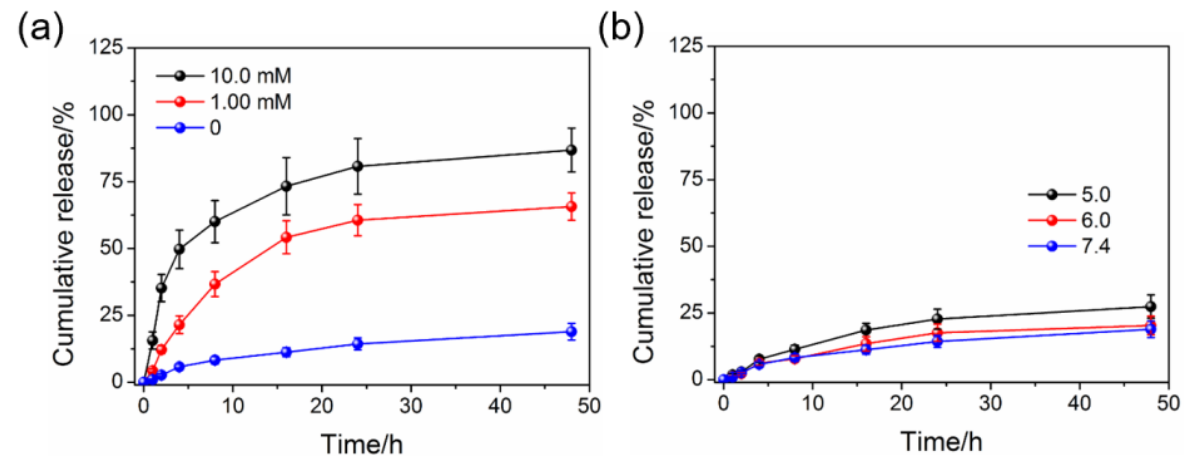

Figure S21. (a) Drug release curves of PA from Pt NPs@PA/DOX with or without different concentrations of $\mathrm{H}_{2} \mathrm{O}_{2}$. (b) Drug release curves of PA from Pt NPs@PA/DOX at different pH values.

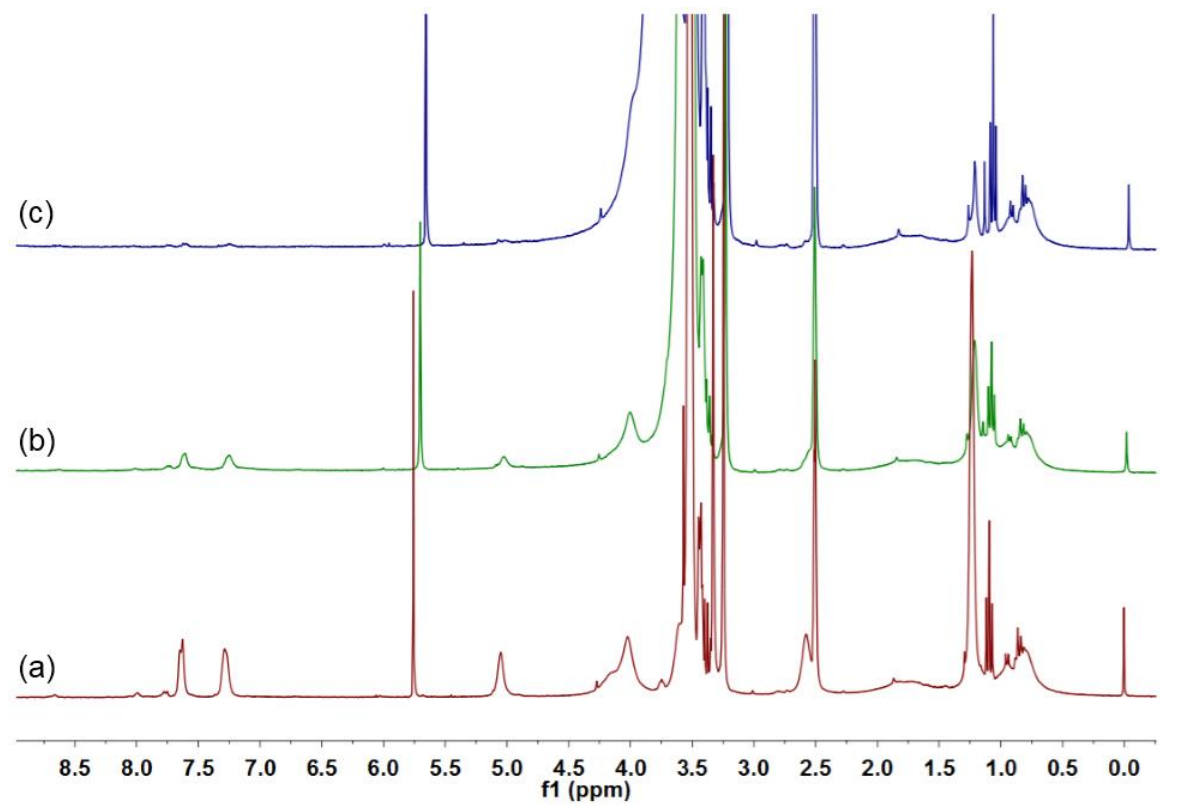

Figure S22. ${ }^{1} \mathrm{H}$ NMR spectra recorded for $\mathrm{H}_{2} \mathrm{O}_{2}$-responsive decomposition of Pt-PBEMA- $\boldsymbol{b}$-POEGMA after incubation for (a) 0, (b) $3 \mathrm{~min}$, and (c) $5 \mathrm{~min}$ in the presence of $1.00 \mathrm{mM} \mathrm{H}_{2} \mathrm{O}_{2}$. 


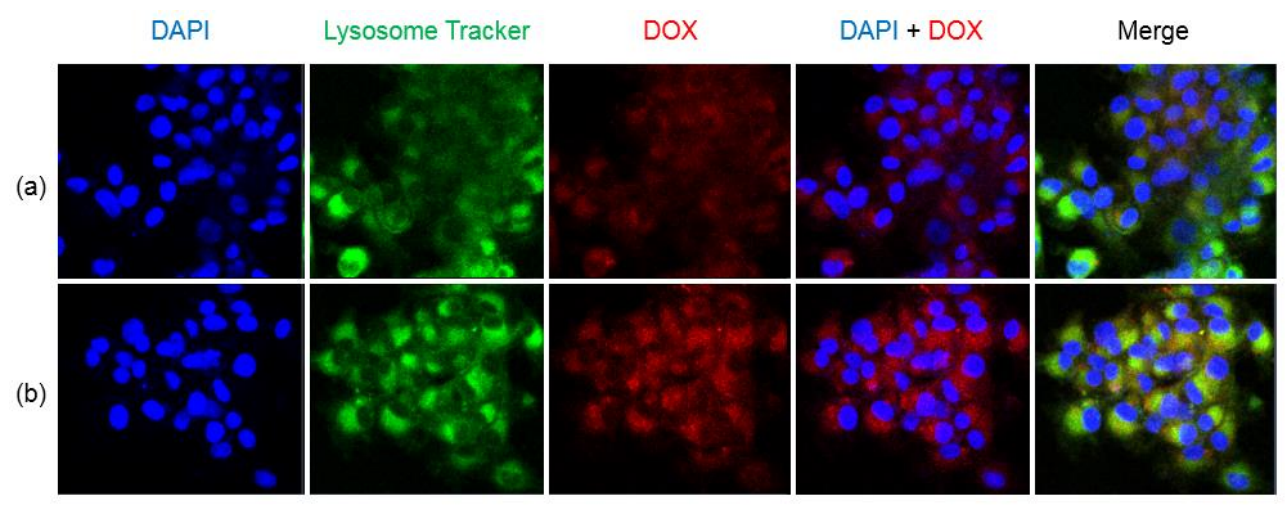

Figure S23. CLSM images of the HeLa cells incubated with $n$ Pt NPs@PA/DOX for (a) $4 \mathrm{~h}$ and (b) $8 \mathrm{~h}$.

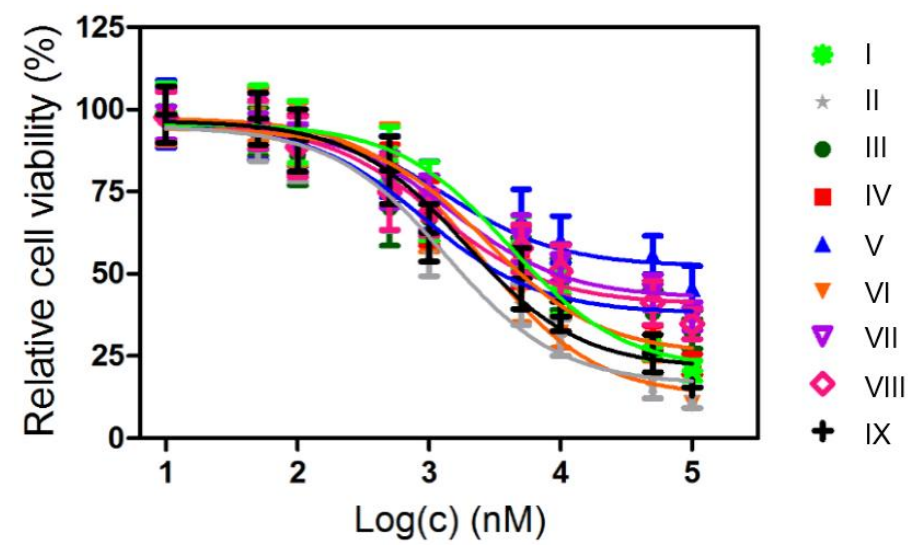

Figure S24. Cytotoxicity of Pt NPs@PA/DOX towards HeLa cells after $48 \mathrm{~h}$ incubation under different conditions. I, PA/DOX = 1:2; II, PA/DOX = 1:4; III, PA/DOX = 2:1; IV, PA/DOX = 1:1; V, PA; VI, DOX; VII, PA/DOX = 8:1; VIII, PA/DOX $=4: 1 ; \mathrm{IX}, \mathrm{PA} / \mathrm{DOX}=1: 8$. 


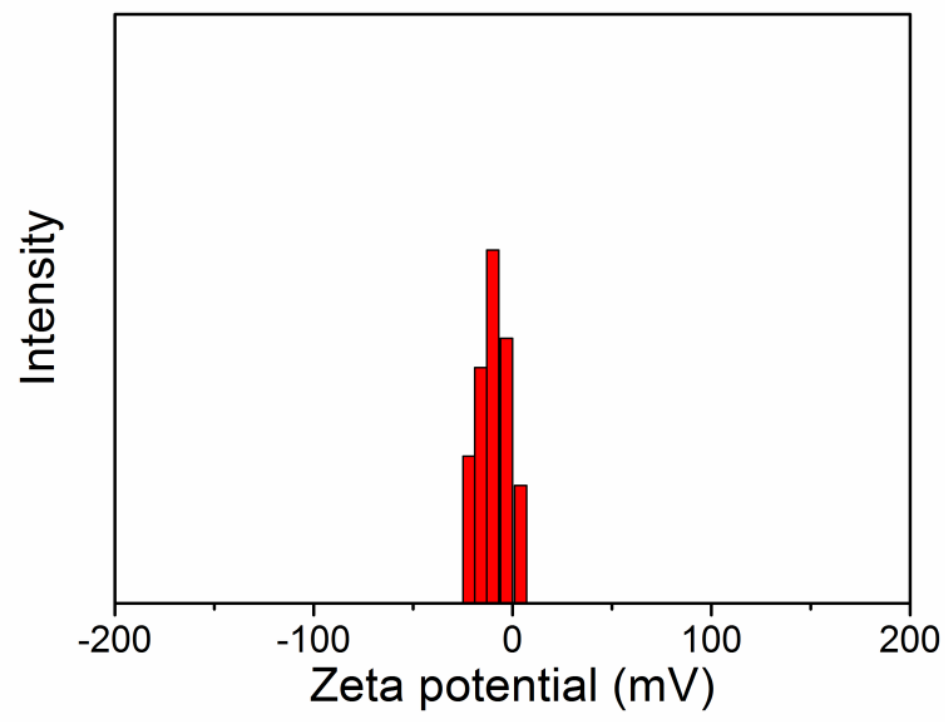

Figure S25. Zeta potential result of Pt NPs@PA/DOX.

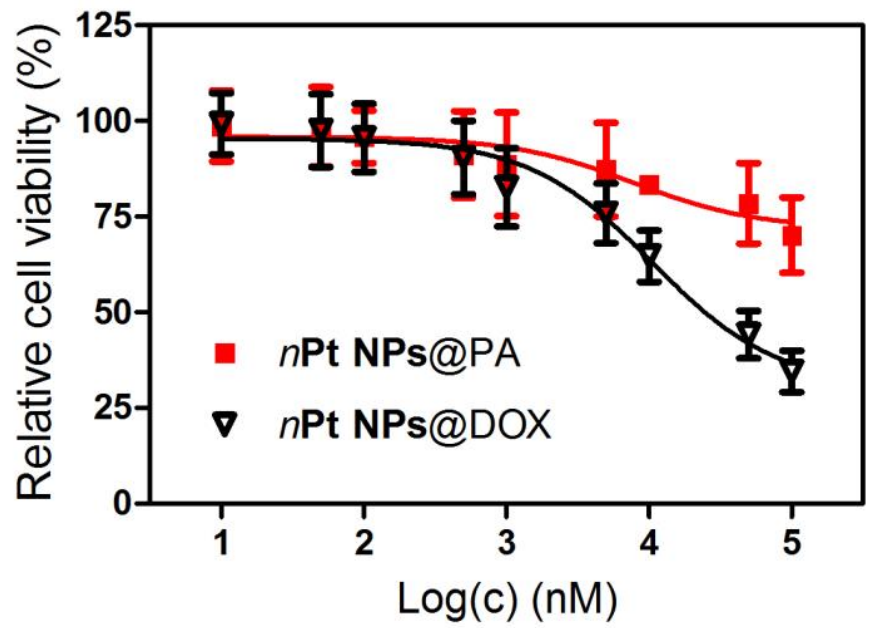

Figure S26. Cytotoxicity of $n$ Pt NPs@PA and $n$ Pt NPs@DOX against HeLa cells after 48 h incubation. 


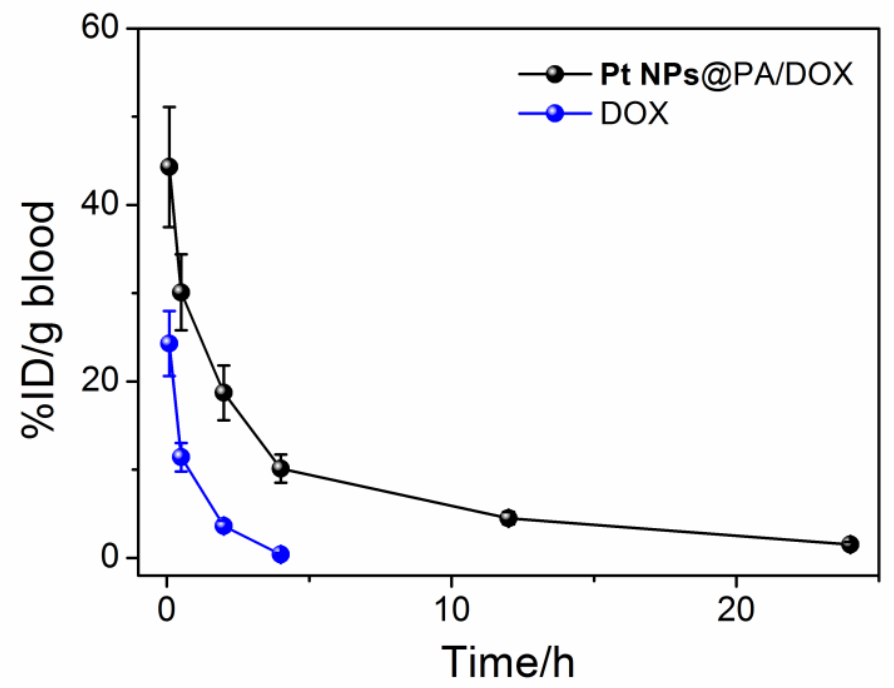

Figure S27. Time-dependent DOX amount in the bloodstream after intravenous injection of free DOX or Pt NPs@PA/DOX.

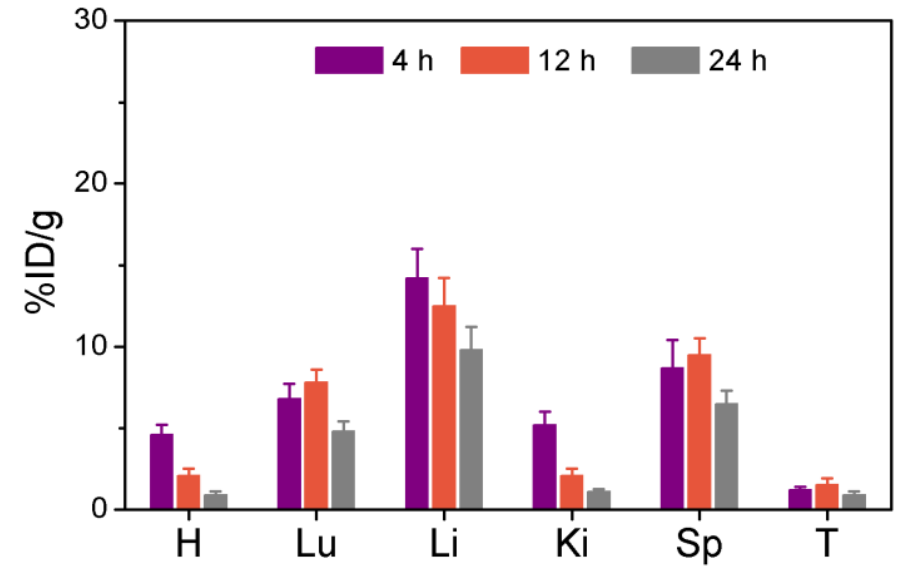

Figure S28. Tissue distribution of DOX in the main organs from the mice treated with free DOX at different post-injection times. H, heart; Lu, lung; Li, liver; Ki, kidney; Sp, spleen; T, tumor. 


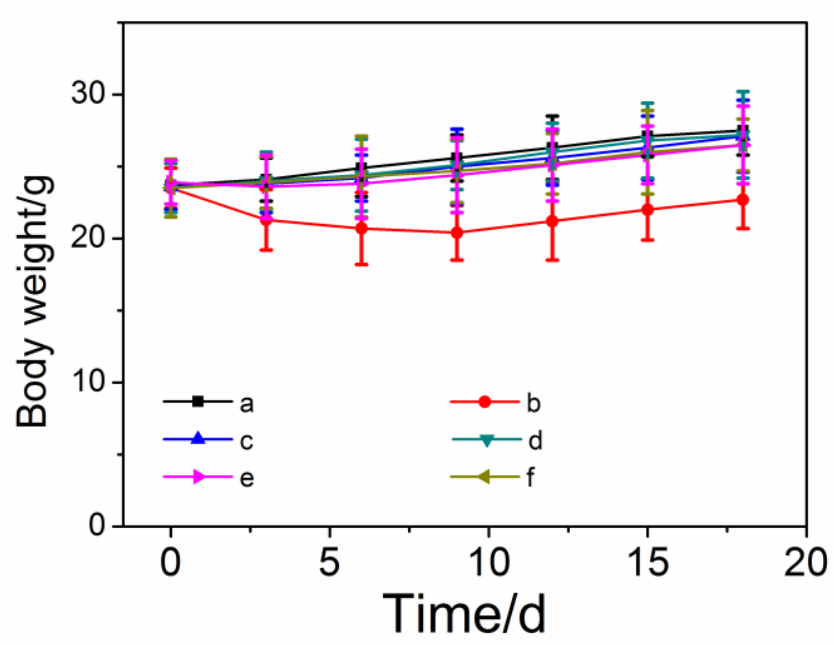

Figure S29. Body weight changes of the mice received different administrations: (a) PBS; (b) DOX; (c) $n \mathbf{P t}$ NPs@PA/DOX; (d) Pt NPs@PA; (e) Pt NPs@DOX; (f) Pt NPs@PA/DOX.

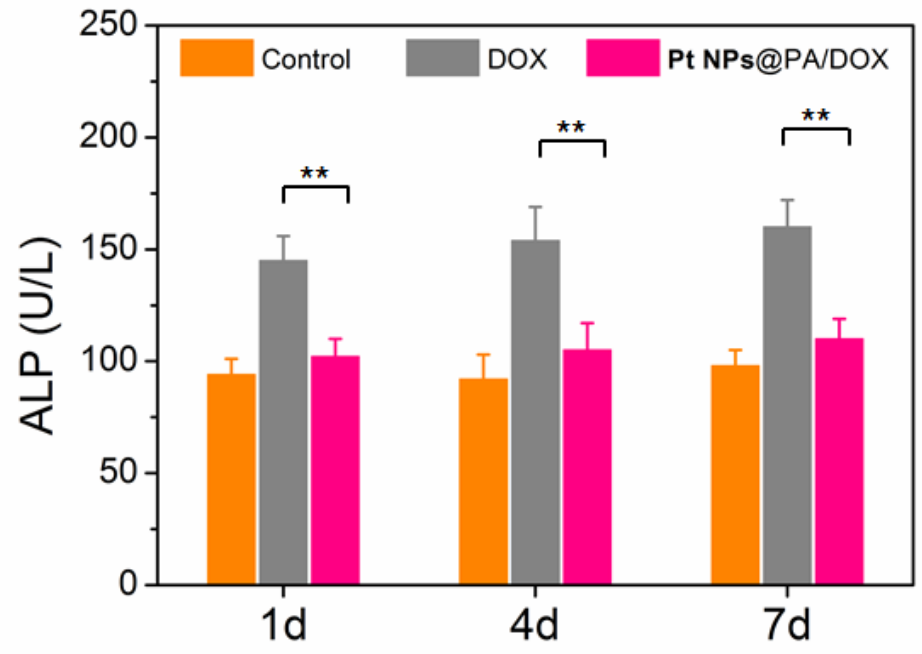

Figure S30. The changes in alkaline phosphatase (ALP) for the mice treated with DOX or Pt NPs@PA/DOX at day 1,4 , and 7 post administration. $* * p<0.01$. 


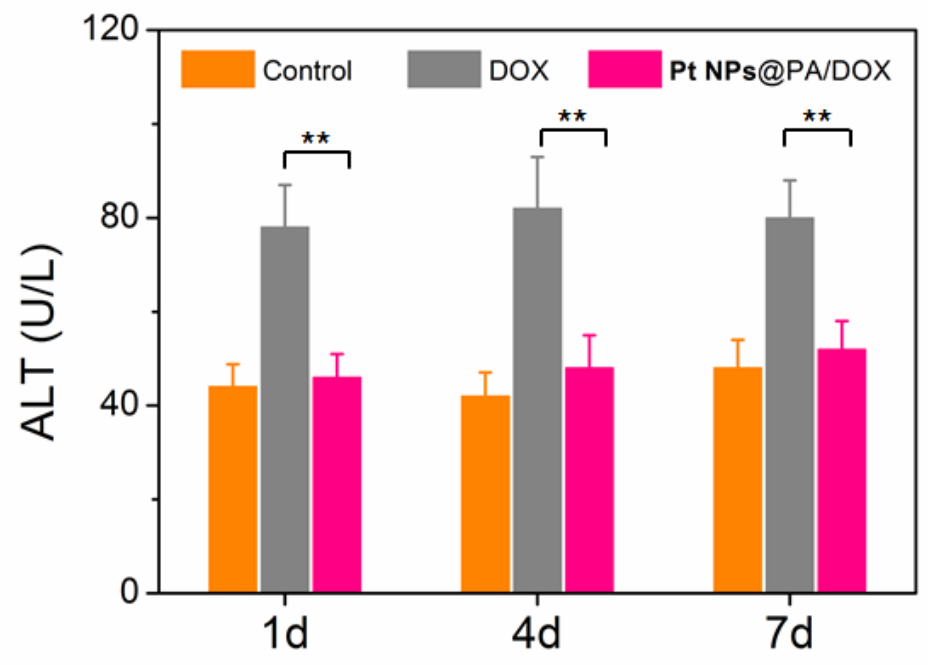

Figure S31. The changes in alanine transferase (ALT) for the mice treated with DOX or Pt NPs@PA/DOX at day 1,4 , and 7 post administration. $* * p<0.01$.

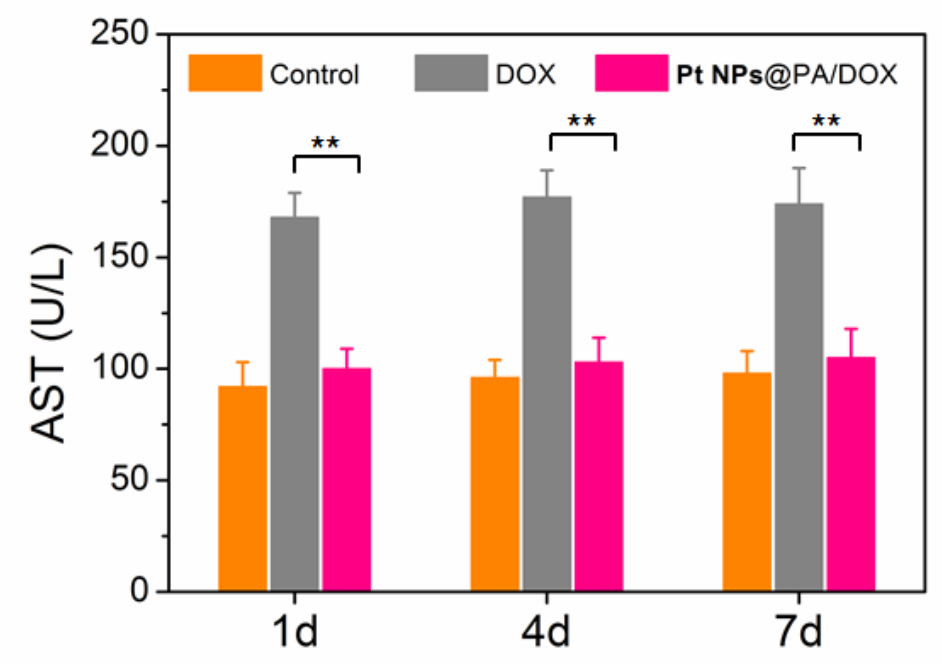

Figure S32. The changes in aspartate transferase (AST) for the mice treated with DOX or Pt NPs@PA/DOX at day 1,4 , and 7 post administration. $* * p<0.01$. 


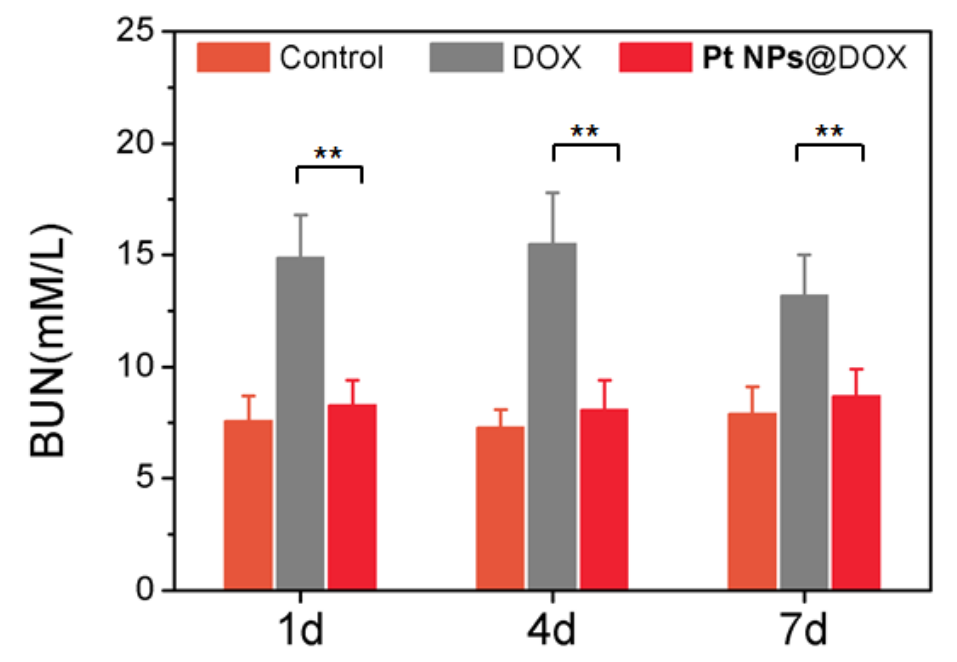

Figure S33. The changes in blood urea nitrogen (BUN) for the mice treated with DOX or Pt NPs@PA/DOX at day 1,4 , and 7 post administration. $* * p<0.01$.

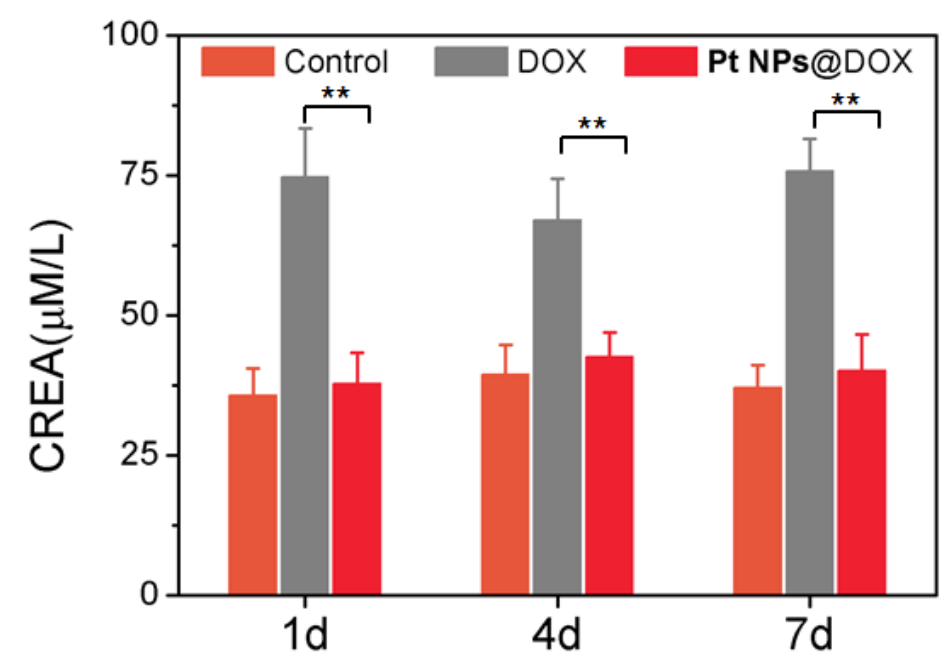

Figure S34. The changes in creatinine (CREA) for the mice treated with DOX or Pt NPs@PA/DOX at day 1, 4, and 7 post administration. $* * p<0.01$. 